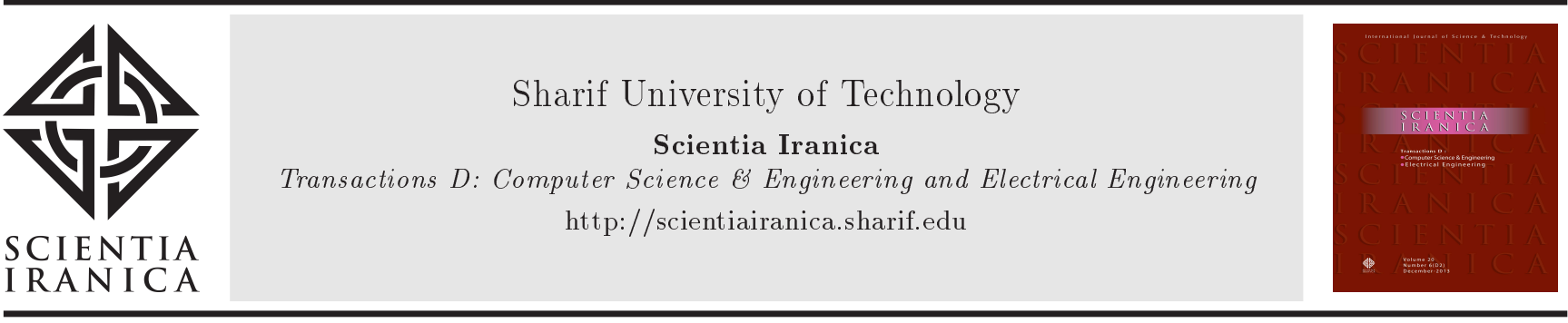

\title{
Placement of electric vehicle charging station and solar distributed generation in distribution system considering uncertainties
}

\author{
A. Pal ${ }^{\mathrm{a}, *}$, A. Bhattacharya ${ }^{\mathrm{b}}$, and A.K. Chakraborty ${ }^{\mathrm{a}}$ \\ a. Department of Electrical Engineering, National Institutes of Technology Agartala, Tripura - 799046, India. \\ b. Department of Electrical Engineering, National Institutes of Technology Durgapur, West Bengal - 713209, India. \\ Received 11 September 2020; received in revised form 11 March 2021; accepted 5 July 2021
}

\section{KEYWORDS \\ Charging station placement; \\ Electric vehicle; \\ Optimization; \\ 2m PEM; \\ Uncertainty.}

\begin{abstract}
The use of Electric Vehicle (EV) to the transport section is increasing and replacing the conventional fossil fuel-based vehicles. Still, EV has not received success due to some limitations such as cost of the vehicle, battery capacity, and availability of charging station. The availability of charging station depends on its geographical location. At the same time, location of the electrical network affects the energy loss and voltage deviation. Therefore, the test system considered here is a road network of the urban area overlapped with a 33-bus radial network. Allocation of EV charging stations and photovoltaic energy resources as renewable distributed generation was attempted simultaneously using 2-layer optimization. Differential Evolution and Harris Hawks Optimization (HHO) are the two tools that were used to solve the problem and the final results were validated using eight other established optimization techniques. $2 \mathrm{~m}$ point estimation method was employed to deal with uncertainties in EV and $P V$. Monte-Carlo simulation was applied to cross verify the performance. The land cost and customer accessibility to charging stations were taken into account to allocate it to proper places. The entire study was performed based on the 24-hour dynamically varying EV flows and $P V$ outputs.
\end{abstract}

(C) 2023 Sharif University of Technology. All rights reserved.

\section{Introduction}

The transport sector devours $65 \%$ of global oil production and contributes $24 \%$ to total $\mathrm{CO}_{2}$ emissions in the world [1]. The Electric Vehicle (EV) is one of the arsenals to encounter air pollution and the crisis of fossil fuels. Due to incremental fuel price, $\mathrm{EV}$ is acquiring rapid attention to the public with

\footnotetext{
*. Corresponding author.

E-mail addresses: arnabpal1994@gmail.com (A.Pal);

bhatta.aniruddha@gmail.com (A. Bhattacharya);

akcall58@gmail.com (A.K. Chakraborty)
}

the support of government's policies, incentive, and developed technologies. In urban cities, EVs are becoming more popular and a significant number of EVs are going to penetrate into power system to charge the batteries inside it. However, EV may not be a solution to environmental pollution and mitigation of fossil fuel crisis, if it gets charged by conventional power sources. Increased power demand due to EV charging would be a cause of more fossil fuel consumption and excess pollution, as thermal/gas based power generations contribute maximum to electricity production [2]. Intensity of this problem can be minimized by incorporating renewable-based Distributed Generation (DG) in the distribution network.

The introduction of numerous EVs to a power 
system distribution network is a challenging task for system planning engineers due to high power demand. The locations of the Electric Vehicle Charging Station (EVCS) play a vital role in EV charging. Proper locations help keep energy loss to a minimum with nominal voltage deviation. The land cost associated with Charging Station (CS) installation depends on the location. Unplanned EVCS placement makes the planning unrealistic and, also, renders distribution network weak due to the violation of voltage and current limit. At the same time, road network largely affects the optimal locations of EVCS. Therefore, the distribution network, as well as road network, should be taken into the consideration for proper allocation of EVCSs. A remarkable attribute associated with EVCS is the uncertainty in EVs' arrival time and uncertain amount of energy requirement by EVs.

Increment in the number of $\mathrm{EV}$ is noticeable mostly in the urban area. Cui et al. [3] placed the ECVS in distribution systems considering different practical constraints related to an urban area. CSs were allocated to the highways of Guwahati city by considering multiple objectives and different softcomputing techniques in [4]. A new approach was presented in [5] for the allocation of CSs in urban areas. Optimal locations of the EVCS were executed in [6] for a geographical location. In [7], EVCSs were placed in the map of London and those in $[8,9]$ were for central Ohio region. The optimal locations and sizes of the CS were decided in the geographical map of Stockholm, Sweden in [10]. In the road map of U.S., fast-charging stations were placed in [11]. Several optimization techniques were used in [12] to determine the locations of EVCS considering the charging demand in an area. A technique was proposed in [13] to estimate the number of required EVCSs and its location in a road network. In $[14,15]$, the optimal locations of EVCS were planned in the map of Beijing. Criteria-based site selection was done in [16]. An analysis was presented in [17] to localize EVCSs in the Google map of Hong Kong considering district-wise population density. In this manner, these referenced notable studies [1826] are determined EVCS locations in different road networks or city's map.

Battery swapping is a strategy to solve the timeconsuming EV charging process, but needs to bear high investment cost. At the Battery Swapping Station (BSS), a fully-charged battery is exchanged with an empty battery. An optimal coordination among charging, discharging, and swapping of the battery in BSS was presented in [27]. The parking lot is another place where EVs are generally parked for a long time with Grid-to-Vehicle (G2V) and Vehicle-to-Grid (V2G) facilities. The $\mathrm{V} 2 \mathrm{G}$ facility provides incentives into the vehicle owner by selling energy to the grid at peak hours. System frequency was regulated using
V2G in [28]. Demand side management was performed in [29] considering EV aggregators. The optimal size of a grid-connected $P V$ allied with EV parking lot was designed using Particle Swarm Optimization (PSO) [30]. In [31], placement of EVCSs/BSSs was executed on modified IEEE 15-bus and 43-bus networks. In [32], a parking lot was allocated to a 9-bus test distribution system. In $[33,34]$, CS was allocated along with DG. Places and sizes of CS were determined in [35]. In [36], DG and parking lots were placed in an optimal location in the distribution network to minimize the power loss. Authors in [37-40] allocated CS optimally to a distribution network.

In [41], the EVCSs were placed in the distribution network of Allahabad city via hybrid optimization based on installation cost and power quality. Twolayer optimization was utilized in [42] to allocate CSs in a 33-bus radial distribution system. The first layer is for cost minimization of charging/discharging, and the second layer is for reactive power management. In [43], demand response was considered in planning of the CSs. EVCSs were installed optimally in the IEEE 123 distribution system in [44] to minimize different costs associated with CS, such as investment, operation, and maintenance, as well as power loss. Costs were minimized by this study [45] through appropriate locations and sizes of EVCS. CS setup was found optimally in [46] by various cost minimization. Sadeghi Barzani et al. [47] minimized the total cost to supply the charging demand of EVs by allocating the EVCS. Cost minimization was also taken in $[48,49]$ to allocate CSs. In [50,51], road network overlapped with distribution systems to allocate CSs using softcomputing techniques. The maximum EVs were served in [50] and the power loss and voltage deviation were minimized. Zhang [51] located the CSs at optimal locations in Beijing by minimizing power loss and cost. In [52], the capacity of the $\mathrm{V} 2 \mathrm{G}$ supported CS was optimized in the IEEE 54 distribution system. Optimal scheduling of G2V and V2G was performed and CS's locations were determined in [53]. The battery energy storages were considered along with EV and EVCS in [54-57]. Researchers in [58-60] employed various optimization techniques to plan the CS and distributed renewable generation by minimizing the power loss, cost, etc.

The EV flow and charging demand are uncertain attributes for this work. Markov chain, fuzzy technique, K-means, Monte-Carlo Simulation (MCS), and Point Estimation Method (PEM) are some available techniques for uncertainty modeling. Markov chain modeling tool was utilized in [61] to model the daily usage of CS. Bidding for $\mathrm{V} 2 \mathrm{G}$ was performed in [62] considering uncertainties related to vehicle mobility using a proposed algorithm based on fuzzy linear programming. The EV flow uncertainties were considered 
in [63] using average approximation to place CS in the map of Columbus. Locations of EVCS were determined in a transportation network by handling uncertainties using artificial immune algorithm in [35]. A new stochastic method was proposed in [64] to consider uncertainties of $\mathrm{EV}$ in a parking lot. Different sets of situations were created based on historical data using K-means clustering in [33] to deal with uncertainties of DG and EV for smart CS in a microgrid. Distribution system was expanded in the presence of EVCS using chance constraints for uncertainties in [65]. The uncertainties of EV were dealt with in [66] for demand response program in the parking lot. An algorithm based on Monte Carlo was developed in [49] to capture the uncertain driving pattern to allocate CS with low costs in a geographical map. MCS was employed in $[67,68]$ to handle the uncertainties of Plugin Hybrid Electric Vehicle (PHEV). However, most of these techniques are subject to drawbacks including high computational time and complexity in terms of handling a large number of uncertain variables' long calculation time for MCS, and difficulty in predicting $\mathrm{K}$-value in K-mean algorithm and complexity in chance constraints [69]. The $2 \mathrm{~m}$ Point Estimation Method ( $2 \mathrm{~m}$ PEM) is advantageous in modeling uncertainties in a simple way with shorter computational time and high accuracy [70]. The modeling of uncertainties was achieved in [70] using 2m PEM for uncertain $P V$ power output. This method has not been applied yet to EVCS planning in the available literature.

A summary of the research gap is identified from the literature and new factors considered in this paper are presented below:

i) Research articles on CS allocation are not sufficient for practical implementation. Most of the research works are on placement either from the electrical background where EVCS has been placed in the power system network or from the transportation department where EVCS has been allocated in the map/road network. In this work, EVCSs are allocated to a distribution network considering different weightage scores of the locations. The weightage scores are determined based on market area, road junctions, and household area in the road network where EV density is higher. The proposed work targets a 33-node radial distribution test system overlaid with a traffic system;

ii) Much of the literature has considered either EVCS cost or electrical parameters (power loss and voltage deviance). However, the allocation problem will be realistic as many influencing factors are considered. Therefore, in this work, the weightage of the locations and land cost have been taken along with electrical parameters to get more realistic result. Land cost has been minimized to reduce the investment cost for EVCS, while weightage has been maximized to place the EVCS where much more traffic is attracted and is able to serve the maximum number of vehicles. Moreover, renewable-based DGs have been allocated in this work along with EVCSs to reduce energy loss and to improve the voltage profile;

iii) To the best of authors' knowledge, only few published papers $[50,51]$ are available where road and electrical network both have been considered. However, in both of these research papers, uncertainty has not been taken into consideration. Whereas EV flows, distances travelled by vehicles, energy requirement of each $\mathrm{EV}$, and arrival time of EVs are uncertain. In this paper, possible uncertainties associated with the $\mathrm{EV}$ and $P V$ power output are considered in problem formulation to make this work more realistic. The most suitable uncertainty handling tool, namely $2 \mathrm{~m}$ PEM [70,71], is adopted to deal with uncertainties in a better manner with different probable scenarios. The final solution is cross verified with MCS [69] and real data to check the performances;

iv) EV flow is a 24-hour event that has not been taken by many of the research studies. If minimization of power loss has been taken as an objective, the optimal location of EVCS may change following the variation of the time slot, because power loss depends on the load and the load at EVCS changes over time due to different arrival and departure times of EVs. In this work, 24-hour slots are taken for appropriate load variation at $\mathrm{CS}$ and generation variation of $P V$. Therefore, minimization of energy loss, rather than power loss minimization, is considered to be one of the objectives of the problem formulation;

v) Simultaneous allocation of EVCS and solar DG is designed in 2-layer optimization and solved by soft-computing techniques. However, uncertainties create a massive computational load and consume a huge amount of time to solve the problem. Differential Evolution (DE) [72] can solve the optimization problem in a shorter amount of time for convergence [73]. Therefore, DE has been employed for this problem. Moreover, a recent optimization technique, Harris Hawks Optimization (HHO), has also been implemented to verify the optimal solutions obtained from DE. It was established in [74] that HHO performed better than other well-known optimization techniques. It is obvious that soft computing techniques take much more time. Though, HHO has been selected since the solution to the present problem is not real time; rather, it is a pre-decided solution. 
The final results are validated using different benchmarked optimization techniques, which are Genetic Algorithm (GA), PSO, Grey Wolf Optimizer (GWO), Biogeography-Based Optimization (BBO), Symbiotic Organisms Search (SOS), Honey Bee Colony (HBC), Backtracking Search Optimization Algorithm (BSA), and Henry Gas Solubility Optimization (HGSO).

The above factors and solution methodologies are considered in this research work to make the problem practical and achieve robust solutions. The remaining part of the paper is organized as follows. Section 2 presents the problem formulation with objective functions and constraints. Section 3 proposes the solution methods, i.e., 2m PEM, 2-layer optimization, and procedure to obtain the best non-dominated result. Section 4 mentions input data for this work and shows the simulation results of different case studies with discussion. Section 5 concludes the paper.

\section{Problem formulation}

In Subsection 2.1, formulations of the four initial objectives are shown. Subsection 2.2 presents all the constraints for this problem. The objectives depend on deterministic variables as well as scholastic variables. The deterministic variables, i.e., locations of the EVCS and solar DG, need to be decided optimally and the values of uncertain variables are to be taken following the distribution function. Subsection 2.3 shows the use of uncertain variables in the problem formulation. The final objective functions are given in Section 3 using 2m PEM method to deal with the uncertainties via the assessment of different probable scenarios.

\subsection{Objectives of the work}

\subsubsection{Objective 1}

Minimization of energy loss is considered as Objective 1, which can be expressed as follows:

$$
f_{1}=\text { Eloss }=\sum_{t=1}^{24} \operatorname{Ploss}^{(t)} \times \Delta t,
$$

where Ploss ${ }^{(t)}$ is the total active power loss of the system at the $t$ th hour, $\Delta t$ is the time duration of hour 1:

$$
P l o s s^{(t)}=\sum_{b r=1}^{N_{b r}}\left(I_{b r}^{(t)}\right)^{2} \times R_{b r}
$$

where $I_{b r}^{(t)}$ is current in the $b r$ th branch at the $t$ th hour, $R_{b r}$ is the resistance of the $b r$ th branch, and $N_{b r}$ is the total branch present in the network.

\subsubsection{Objective 2}

Minimization of 24-hour voltage deviation is taken as
Objective 2. The 24-hour voltage deviation of the distribution network is obtained by:

$$
f_{2}=V d=\sum_{t=1}^{24} V d^{(t)}
$$

where $V d$ is the total voltage deviation for 24 hours and $V d^{(t)}$ is voltage deviation at the $t$ th time as follows:

$$
V d^{(t)}=\sum_{b u=1}^{N_{b u}} a b s\left(1-V_{b u}^{(t)}\right),
$$

where $V_{b u}^{(t)}$ is voltage at the buth bus at the $t$ th hour and $N_{b u}$ is the total number of buses in the distribution network.

To calculate the output different parameters such as voltages and currents, the backward-forward sweep loadflow was performed.

\subsubsection{Objective 3}

Market area, house hold area, and road junctions are the vital places where EV density is high. The importance of these locations is indicated by weightages [75]. Here, the objective is maximization of weightage to provide EV charging services to maximum users:

$$
\begin{aligned}
& f_{3}=W=\sum_{S=1}^{N_{l}} \alpha, \\
& \text { where } \quad \alpha=0, \quad \text { if } S \notin \text { locations of the } C S ; \\
& \alpha=w_{S}, \quad \text { if } S \in \text { locations of the } C S, \text { (5) }
\end{aligned}
$$

where $W$ is the summation of weightages of all the locations where the EVSCs are to be placed, $w_{S}$ is the weightage of the location of the $S$ th EVCS, and $N_{l}$ is the total number of locations.

\subsubsection{Objective 4}

The land cost is a significant aspect for the setting up EVCS in an urban area. Few places that are vital for CS may be quite costly, being the reason why land cost minimization was considered as Objective 4 to reduce the overall investment:

$$
\begin{aligned}
& f_{4}=C=\sum_{S=1}^{N_{l}} \beta, \\
& \text { where } \quad \beta=0, \quad \text { if } S \notin \text { locations of the } C S ; \\
& \qquad \beta=c_{S}, \quad \text { if } S \in \text { locations of the } C S,
\end{aligned}
$$

where $C$ is the total land cost of all the EVCSs and $c_{S}$ is the land cost of the $S$ th location.

\subsection{Constraints}

Constraints for distribution network are as follows:

- Power balance constraint: The supplied power 


$$
\begin{aligned}
& P_{g b}-P_{d b}-\left|V_{b}\right| \sum_{b u=1}^{N_{b u}}\left|Y_{b, b u}\right|\left|V_{b u}\right| \cos \left(\delta_{b}-\delta_{b u}-\theta_{b, b u}\right)=0, \quad b=1,2, \cdots, N_{b u}, \\
& Q_{g b}-Q_{d b}-\left|V_{b}\right| \sum_{b u=1}^{N_{b u}}\left|Y_{b, b u}\right|\left|V_{b u}\right| \sin \left(\delta_{b}-\delta_{b u}-\theta_{b, b u}\right)=0, \\
& Y_{b, b u}= \begin{cases}-y_{b, b u}, & \text { if } b \neq b u \\
\left(y_{b 1}+y_{b 2}+\cdots+y_{b N_{b u}}\right), & \text { if } b=b u \\
0, & \text { if no branch between } b \text { and } b u \text { bus }\end{cases}
\end{aligned}
$$

Box I

should be equal to the loads and losses. This constraint is applicable to active and reactive powers and is calculated by Eqs. (7) to (9), shown in Box I, where $P_{g b}$ and $Q_{g b}$ are the active and reactive power generation of bus $b ; P_{d b}$ is active power demand; and $Q_{d b}$ is reactive power demand of the $b$ th bus. $P_{d b}$ value is calculated using Eq. (22) and replaced by $P_{b u}$ during the placement of the EVCS. From Eq. (25), $P w_{p v}$ will be added in Eq. (7) as negative load during DG placement. $Y_{b, b u}$ is the element of the admittance matrix, where $y_{b, b u}$ is the branch admittance between $b$ th and $b u$ th buses. $V_{b}$ and $V_{b u}$ are voltages at buses $b$ and $b u$, respectively. $\delta_{b}$ is the phase angle of voltage at the $b$ th bus and $\delta_{b u}$ is the phase angle of voltage at the buth bus. $\theta_{b, b u}$ is the angle of $y_{b, b u}$ when represented in polar form.

- Voltage limit constraint: The voltage constraint is taken to keep the bus voltages within permissible limits:

$$
V_{\min } \leq V_{b u} \leq V_{\max }, \quad b u=1,2, \cdots, N_{b u} .
$$

- Thermal limit constraint: The thermal limit of the branch should be less than the upper bound as represented below:

$$
\left|S_{b r}\right| \leq\left|S_{b r}^{\max }\right|, \quad b r=1,2, \cdots, N_{b r},
$$

where $S_{b r}$ is apparent power of branch $b r$ and $S_{b r}^{\max }$ is the highest allowable apparent power of branch $b r$.

- Branch current limit constraint: Branches are having some maximum capacity to carry the current. To restrict it within the maximum limit, the constraint is imposed as follows:

$$
\left|I_{b r}\right| \leq I_{b r}^{\max }, \quad b r=1,2, \cdots, N_{b r}
$$

where $I_{b r}$ is the branch current of the brth line and $I_{b r}^{\max }$ is the maximum allowable current limit through the brth line.
- Short circuit constraint: Due to the presence of the DGs, the short-circuit constraint [76] has been taken into account:

$$
S C L_{b u} \leq S C L^{\max }, \quad b u=1,2, \cdots, N_{b u},
$$

where $S C L_{b u}$ is the short-circuit level at the buth bus and $S C L^{\max }$ is the maximum allowable shortcircuit current. Short-circuit level can be calculated as follows [76].

Constraint for road network [75] is as follows:

- Zone constraint: The constraint has been considered for allocation of each EVCS in each zone in the urban area as follows:

$$
S_{i} \in Z_{i}
$$

where $S_{i}$ is the $i$ th EVCS and $Z_{i}$ is the $i$ th zone.

Constraints for EVs and EVCSs [75] are as follows:

- State Of Charge (SOC) constraint: The permissible SOC levels of EV should be conserved to maintain good conditions of the battery, where the minimum level is $25 \%$ and maximum level is $90 \%$ :

$$
25 \% \leq S O C \leq 90 \%
$$

- Number of charging port constraint:

$$
\begin{aligned}
& N_{\text {port }}=\max \left(n v_{G 2 V}^{(t)}+n v_{G 2 V}^{(t)}\right), \\
& t=1,2, \cdots, 24
\end{aligned}
$$

where $N_{\text {port }}$ is the quantity of charging ports at an EVCS; $n v_{G 2 V}^{(t)}$ and $n v_{V 2 G}^{(t)}$ are quantities of $\mathrm{EV}$ in $\mathrm{G} 2 \mathrm{~V}$ and $\mathrm{V} 2 \mathrm{G}$ modes, respectively, at the $t$ th time. Queue of EVs at EVCS is not desirable. Thus, the quantity of ports is equal to maximum EV present at an EVCS. 


\subsection{Calculation with uncertain variables}

Uncertain variables associated with EV and DG affect the parameters of the above-mentioned equations of electrical system, because uncertain variables of $\mathrm{EV}$ and DG create uncertain loads at EVCS as well as uncertain generations from solar DGs.

\subsubsection{Reflection of uncertain variables related to $E V$}

The following parameters are considered as uncertain for all EVs:
i) Arrival SOC;
ii) Arrival time;
iii) Each trip distance;
iv) Daily mileage.

Energy demand by the EVs and departure time of the EVs are calculated using the above-mentioned uncertain variables. Table 1 presents the distributions followed by the above-mentioned uncertain variables and their mean, Standard Deviation (SD), and maximum and minimum values.

Energy demand (kWh) by the EV can be calculated as follows [77]:

$R e q_{v}^{e n g}= \begin{cases}\left(R e q_{v}^{s o c} \times B c_{v}\right) / \eta_{c h}, & \text { if } G 2 V \text { mode } \\ \left(R e q_{v}^{s o c} \times B c_{v}\right) \times \eta_{\text {dis }}, & \text { if } V 2 G \text { mode }\end{cases}$

where $R e q_{v}^{s o c}, R e q_{v}^{e n g}$, and $B c_{v}$ indicate required SOC in percentage, required energy in $\mathrm{kWh}$, and battery capacity in $\mathrm{kWh}$ of the $v$ th vehicle, respectively. $\eta_{c h}$ and $\eta_{\text {dis }}$ are charging and discharging efficiency rates that have been considered $95 \%$ and $90 \%$ respectively. $R e q^{s o c}$ is calculated in percentage [77] as follows:

$$
\operatorname{Req}_{v}^{s o c}= \begin{cases}1-A_{v}^{s o c}, & \text { if } D_{v}^{s o c}>1 \\ D_{v}^{s o c}-A_{v}^{s o c}, & \text { if } A_{v}^{s o c}<D_{v}^{s o c}<1 \\ 0, & \text { if } A_{v}^{s o c}=D_{v}^{s o c} \\ -\left(A_{v}^{s o c}-D_{v}^{s o c}\right), & \text { if } 0.25<D_{v}^{s o c}<A_{v}^{s o c}\end{cases}
$$

where $A_{v}^{s o c}$ and $D_{v}^{s o c}$ are arrival SOC and departure SOC of the $v$ th vehicle. Depending on uncertainties, $\mathrm{EV}$ operates in the $\mathrm{V} 2 \mathrm{G}$ mode when arrival SOC is higher than the departure SOC. Arrival SOCs have been randomly created in line with the truncated distribution function [66,78]. Departure SOC [77] is expressed as:

$$
D_{v}^{s o c}=\left(S T D_{v} / A E R_{v}\right)+0.25,
$$

where $A E R_{v}$ is all-electric range of the $v$ th vehicle. Minimum SOC limit has been set to $25 \%$ in this work. The subsequent trip distance of the $v$ th EV [77] is represented by $S T D_{v}$, which can be obtained as follows:

$$
S T D_{v}=d m_{v}-e t d_{v},
$$

where daily mileage is $d m_{v}$ and each trip distance is etd $v$ of the $v$ th $\mathrm{EV}$, which are randomly created from the respective distribution functions. Load at an EVCS at the $t$ th hour $\left(\right.$ Load $\left.^{(t)}\right)$ is calculated in $\mathrm{kW}$ as:

$$
\text { Load }^{(t)}=\sum_{v=1}^{n v_{G 2 V}^{(t)}} C_{r}-\sum_{v=1}^{n v_{V 2 G}^{(t)}} D_{r}
$$

where $C_{r}$ is the charging rate in the $\mathrm{G} 2 \mathrm{~V}$ mode and $D_{r}$ is the discharging rate in the $\mathrm{V} 2 \mathrm{G}$ mode.

As a final outcome, the entire load demand at the buth bus of the distribution network can be expressed as follows:

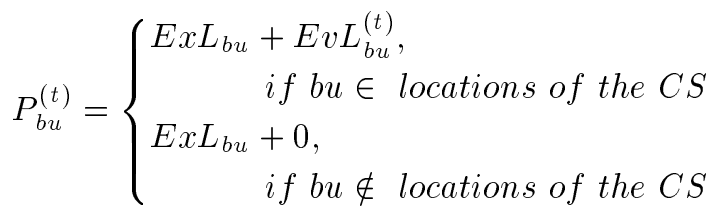

where $E x L_{b u}$ is existing load at the buth node; $E v L_{b u}^{(t)}$ is the load for the EVCS if it is connected to the buth bus. $E v L_{b u}^{(t)}$ is zero if there is no $\mathrm{EV}$ at the $t$ th time. $P_{b u}^{(t)}$ is deducted from the total load in Eq. (7).

Departure time $\left(D_{v}^{\text {time }}\right)$ of the $v$ th vehicle is determined as follows:

$$
D_{v}^{\text {time }}=A_{v}^{\text {time }}+R e q_{v}^{\text {time }},
$$

where $R e q_{v}^{\text {time }}$ is the required time for the $v$ th $\mathrm{EV}$ to attain its desired SOC level, $A_{v}^{\text {time }}$ is the arrival time of the $v$ th vehicle at CS. Required time for $\mathrm{G} 2 \mathrm{~V}$ (charging) or $\mathrm{V} 2 \mathrm{G}$ (discharging) is obtained as follows:

$$
R e q_{v}^{\text {time }}= \begin{cases}\operatorname{Re} q_{v}^{e n g} / C_{r}, & \text { if } \mathrm{G} 2 \mathrm{~V} \\ a b s\left(R e q_{v}^{e n g} / D_{r}\right), & \text { if } \mathrm{V} 2 \mathrm{G}\end{cases}
$$

Table 1. Distribution details for uncertain properties of Electric Vehicle (EV).

\begin{tabular}{lclcccc}
\hline Uncertain factor & Unit & \multicolumn{1}{c}{ Distribution } & Mean & SD & Min & Max \\
\hline Arrival time & Hour & Truncated Gaussian [66] & 12 & 4 & 4 & 23 \\
Arrival SOC & $\%$ & Truncated Gaussian [66,77] & 50 & 25 & 25 & 90 \\
Daily mileage & $\mathrm{km}$ & Normal [78] & 55 & 10 & 0 & - \\
Each trip distance & $\mathrm{km}$ & Normal [78] & 19.25 & 7.95 & 0 & - \\
\hline
\end{tabular}




\subsubsection{Reflection of uncertain variables related to solar $D G$}

The main stochastic variable for $P V$ is solar irradiance $\left(\mathrm{kW} / \mathrm{m}^{2}\right) . P V$ cell temperature is also uncertain, but it depends on irradiance only. $P V$ power output at the $t$ th hour $\left(P w_{p v}^{(t)}\right)$ will be added to Eq. (7) as a negative load and it can be expressed as [79]:

$$
P w_{p v}^{(t)}=P v_{v a r i}^{(t)} \times P w_{p v},
$$

where $P v_{\text {vari }}$ is the 24-hour variation of solar irradiance in p.u., as can be seen in [79]. Therefore, at the endpoint $P V$, power output $\left(P w_{p v}\right)$ is uncertain calculated from solar irradiance [80] by:

$$
P w_{p v}=N_{p} \times F_{f} \times V_{i r} \times I_{i r},
$$

where $N_{p}$ is the total number of $P V$ modules $F_{f}$ is the fill factor that can be presented as follows:

$$
\begin{aligned}
& F_{f}=\frac{V_{m p} \times I_{m p}}{V_{o c} \times I_{s c}}, \\
& V_{i r}=V_{o c}-C_{v} \times t_{c e l l}, \\
& I_{i r}=i r_{a v g} \times\left\{I_{s c}+C_{i}\left(t_{c e l l}-25\right)\right\}, \\
& t_{c e l l}=t_{a m b}+\left(i r_{a v g} \times \frac{t_{n o m}-20}{0.8}\right),
\end{aligned}
$$

where $V_{m p}$ and $I_{m p}$ are maximum power point voltage and current, respectively. $V_{o c}$ and $I_{s c}$ are opencircuit voltage and short-circuit current, respectively. $i r_{\text {avg }}$ is the average solar irradiance and $t_{\text {cell }}$ is the cell temperature in ${ }^{\circ} \mathrm{C}$. $C_{v}$ and $C_{i}$ are voltage and current temperature coefficient, respectively. $t_{\text {nom }}$ is the nominal operating temperature of $P V$ cell and $t_{a m b}$ is ambient temperature. The solar irradiance follows beta distribution [80], which can be demonstrated as follows:

$$
f(i r)=\left\{\begin{array}{l}
\frac{\Gamma\left(\alpha_{i r}+\beta_{i r}\right)}{\Gamma\left(\alpha_{i r}\right) \Gamma\left(\beta_{i r}\right)} \times i r^{\left(\alpha_{i r}-1\right)} \times(1-i r)^{\left(\beta_{i r}-1\right)} \\
0 \leq i r \leq 1 ; \alpha_{i r} \geq 0 ; \beta_{i r} \geq 0 \\
\quad \text { else }
\end{array}\right.
$$

where $\alpha_{i r}$ and $\beta_{i r}$ are beta shape parameters. $\mu_{i r}$ and $\sigma_{i r}$ are the mean and SD of solar irradiance, respectively, as determined below:

$$
\begin{aligned}
\mu_{i r} & =\frac{\alpha_{i r}}{\left(\alpha_{i r}+\beta_{i r}\right)}, \\
\sigma_{i r} & =\sqrt{\frac{\mu_{i r}^{2}\left(1+\mu_{i r}\right)}{\left(\alpha_{i r}+\mu_{i r}\right)}} .
\end{aligned}
$$

\section{Solution methodology}

The locations of EVCS and DG on the distribution network affect power loss and voltage. Moreover, locations on the road network decide the land cost and weightage. Therefore, all the four objectives depend on the same decision variables which are the locations of the EVCS and DG. The solution of the proposed formulation has been achieved in two different layers. Allocation of the EVCS is modeled in the upper layer and DG in the lower layer of the optimization. The modified objective functions $\left(f_{11}, f_{22}, f_{33}, f_{44}\right)$ are formulated in Subsection 3.4 from the four objectives mentioned in Subsection 2.1.

In the case of applying optimization with an individual single objective, some other remaining objectives may move toward the worst direction. Therefore, individual optimization of those four objectives may represent a suitable solution in a practical scenario. This scenario is dependent on the priority of the network administrator and system panning engineer and their protocol. One may give importance to either energy loss, cost, or energy loss and cost simultaneously in a compromising manner to solve the problem or some distribution company may not allow voltage deviation. For this reason, a combination of several objectives needs to be met instead of a single objective.

\subsection{Normalization of the objective function}

In case of multiple objectives, the values of the individual objective function should be normalized to adjust them, so that none of the objective function dominate the other during the process of optimization. This is because of the reason that four objectives are not having the same unit. In this work, normalization has been done after modification of the objective functions. The normalization of the objective function can be expressed as follows:

$$
f_{i i}^{n m}= \begin{cases}\frac{f_{i i}-f_{i i}^{\min }}{f_{i i}^{\text {max }}-f_{i i}^{\min }}, & \text { if } f_{i i} \text { to be minimized } \\ \frac{f_{i i}^{\max }-f_{i i}}{f_{i i}^{\text {max }}-f_{i i}^{\min }}, & \text { if } f_{i i} \text { to be maximized }\end{cases}
$$

where $f_{i i}^{n m}$ is the normalized value and $f_{i i}$ is the original value of the $i$ th objective after applying the $2 \mathrm{~m} \mathrm{PEM}, f_{i i}^{\min }$ is the minimum value, and $f_{i i}^{\max }$ is the maximum value of the modified $i$ th objective.

\subsection{Objective function for upper layer optimization}

Four normalized modified objective functions were taken for EVCS allocation in the upper layer of optimization. The multi-objective problem was converted into a single-objective one $\left(F_{1}\right)$. Four weights $\left(\omega_{1}\right.$, $\left.\omega_{2}, \omega_{3}, \omega_{4}\right)$ were multiplied by $f_{11}^{n m}, f_{22}^{n m}, f_{33}^{n m}, f_{44}^{n m}$, respectively. The single objective was formulated as follows:

$$
\min \left(F_{1}\right)=\min \left(\omega_{1} f_{11}^{n m}+\omega_{2} f_{22}^{n m}+\omega_{3} f_{33}^{n m}+\omega_{4} f_{44}^{n m}\right) .
$$


In case an objective is optional according to the protocol/planning strategy, the corresponding part can be eliminated from Eq. (35).

\subsection{Objective function for lower layer optimization}

Two normalized modified objective functions of energy loss and voltage deviation were considered as the minimization problem for the solar DG allocation in the lower layer of the optimization. In this problem, a single-objective function was prepared with the normalized values $\left(f_{11}^{n m}, f_{22}^{n m}\right)$ and weighting coefficients $\left(\omega_{1}, \omega_{2}\right)$ :

$$
\min \left(F_{2}\right)=\min \left(\omega_{1} f_{11}^{n m}+\omega_{2} f_{22}^{n m}\right) .
$$

\subsection{Application of 2m PEM}

The uncertain variables need to be handled efficiently as mentioned in Subsection 2.3. The PEM is an effective statistical algorithm to handle multiple uncertainties. Hong's 2m PEM [71] was employed in the current work. In this technique, the double number of sets of uncertain variables is generated. The initial objective functions are calculated for every set and the mean values are the modified objective functions that were taken into account in optimization. In this subsection, $f_{11}$ and $f_{22}$ changed based on the method mentioned in the previous line.

\subsubsection{Modification of objective function-1 [75]}

Modified objective function $1\left(f_{11}\right)$ is the mean of energy losses ( $\mu$ Eloss) considering uncertainties. This is set to be a minimization problem:

$$
\begin{aligned}
& \min \left(f_{11}\right)=\min (\mu \text { Eloss }), \\
& \mu \text { Eloss }=\text { Eloss }_{1} .
\end{aligned}
$$

$\mathrm{SD}$ of energy loss ( $\sigma$ Eloss $)$ is calculated by:

$$
\sigma \text { Eloss }=\sqrt{\left(E_{\text {loss }}-\left(\text { Eloss }_{1}\right)^{2}\right)},
$$

where Eloss 1 is the first moment and Eloss 2 is the second moment of Eloss. The moments can be evaluated via Eq. (40) as per 2m PEM technique:

$$
\text { Eloss }_{h}=\sum_{l=1}^{m} \sum_{p o=1}^{2}\left(w_{l, p o} \times\left(\text { Eloss }_{l, p o}\right)^{h}\right), \quad h=1,2
$$

where Eloss $h$ is the $h$ th moment of Objective $1 ; w_{l, p o}$ provides two weighting factors by $p o=1,2$; and $m$ denotes the number of uncertain variables:

$$
w_{l, p o}=\frac{(-1)^{p o}}{m} \times \frac{\xi_{R_{l},(3-p o)}}{\xi_{R_{l}, 1}-\xi_{R_{l}, 2}}, \quad \text { po }=1,2,
$$

where $\xi_{R_{l}}$ is the standard location of $R_{l}$.

$$
\begin{aligned}
& \text { Eloss }_{l, p o}=f\left(D_{v}, \mu_{R_{1}}, \mu_{R_{2}}, \cdots, z_{l, p o}, \cdots, \mu_{R_{m}}\right), \\
& \text { po }=1,2 ; l=1,2,3, \cdots, m,
\end{aligned}
$$

where $D_{v}$ is a deterministic variable; $\mu_{R_{l}}$ the mean of the $l$ th uncertain variable; and $z_{l, p o}$ specified locations of the uncertain variable.

The PEM sets are presented in Eq. (43) shown in Box II, where $D$ is the deterministic variable, and $n$ is the number of deterministic variables. $2 \times m$ sets were formed using dual locations $(p o)$ and $m$ loops. Energy loss (Eq. (1)) was assessed for every set and the same deterministic numbers. Locations of the EVCS and solar DG are deterministic variables in this work. Uncertain variables are generated using respective distribution functions.

$$
z_{l, p o}=\mu_{R_{l}}+\left(\xi_{R_{l}, p o} \times \sigma_{R_{l}}\right), \quad \text { po }=1,2,
$$

where $\sigma_{R_{l}}$ is the SD of the $l$ th uncertain variable.

$$
\begin{aligned}
\xi_{R_{l}, p o} & =\frac{\lambda_{R_{l}, 3}}{2}+(-1)^{3-p o} \sqrt{\lambda_{R_{l}, 4}-\frac{3 \lambda_{R_{l}, 3}^{2}}{4}}, \\
p o & =1,2
\end{aligned}
$$

where $\xi_{R_{l}, p o}$ is the poth standard location of $R_{l} ; \lambda_{R_{l}, 3}$

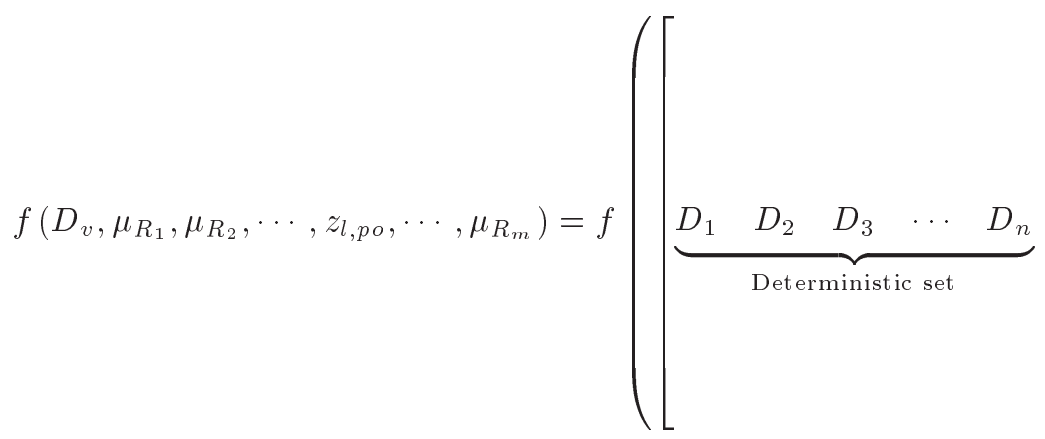

$$
\left.\left.\begin{array}{ccccc}
z_{1,1} & \mu_{R_{2}} & \mu_{R_{3}} & \cdots & \mu_{R_{m}} \\
z_{1,2} & \mu_{R_{2}} & \mu_{R_{2}} & \cdots & \mu_{R_{m}} \\
\mu_{R_{1}} & z_{2,1} & \mu_{R_{3}} & \cdots & \mu_{R_{m}} \\
\mu_{R_{1}} & z_{2,2} & \mu_{R_{3}} & \cdots & \mu_{R_{m}} \\
\vdots & \vdots & \vdots & \vdots & \vdots \\
\mu_{R_{1}}^{\mu_{R_{1}}} & \mu_{R_{2}} & \mu_{R_{3}} & \cdots & \mu_{R_{3}} \\
\underbrace{}_{\text {Stochastic sets }}
\end{array}\right]\right)
$$


represents the coefficient of skewness of $R_{l}$; and $\lambda_{R_{l}, 4}$ is the coefficient of kurtosis of $R_{l}$.

$$
\lambda_{R_{l}, k}=\frac{\mathbb{E}\left[\left(R_{l}-\mu_{R_{l}}\right)^{k}\right]}{\left(\sigma_{R_{l}}\right)^{k}}, \quad k=3,4,
$$

where $\mathbb{E}$ is the notation for expected value and $\mathbb{E}\left[\left(R_{l}-\right.\right.$ $\left.\mu_{R_{l}}\right)^{k}$ ] can be calculated as follows:

$$
\begin{aligned}
& \mathbb{E}\left[\left(R_{l}-\mu_{R_{l}}\right)^{k}\right]=\sum_{j=1}^{N O}\left(R_{l, j}-\mu_{R_{l}}\right)^{k} \times \mathbb{P}\left(R_{l, j}\right), \\
& \quad k=3,4
\end{aligned}
$$

where $R_{l, j}$ is the $j$ th random number from the distribution function based on the historical data; $N O$ is the observation number of $R_{l} . \mathbb{P}\left(R_{l, j}\right)$ represents probability density. $R_{l}$ can be generated via Eq. (48) for the uncertain variable with normal distribution:

$$
R_{l}=\mu_{u v}+\left(\mathbb{Z} \times \sigma_{u v}\right), \quad l=1,2,3, \cdots, m,
$$

where $\mu_{u v}$ is the mean and $\sigma_{u v}$ is the SD of the uncertain variable $(u v) . \mathbb{Z}$ is the standard normal random variable. The probability density of $R_{l}$ is presented as follows:

$$
\mathbb{P}\left(R_{l}\right)=\frac{e^{-\left[\left(R_{l}-\mu_{R_{l}}\right)^{2} / 2 \times\left(\sigma_{R_{l}}\right)^{2}\right]}}{\sqrt{2 \pi \times \sigma_{R_{l}}^{2}}} .
$$

\subsubsection{Modification of Objective Function 2}

Objective Function $2\left(f_{22}\right)$ is to minimize the mean of voltage deviations $(\mu V d)$ considering the uncertainties. This objective is considered to maintain the minimum voltage deviation at each node. $\mu V d$ can be formulated to be the same as $\mu$ Eloss:

$$
\begin{aligned}
& \min \left(f_{22}\right)=\min (\mu V d), \\
& \mu V d=V d_{1} .
\end{aligned}
$$

$\mathrm{SD}$ of voltage deviation $(\sigma V d)$ is calculated by:

$$
\sigma V d=\sqrt{\left(V d_{2}-\left(V d_{1}\right)^{2}\right)}
$$

where $V d_{1}$ is the first moment and $V d_{2}$ is the second moment of $V d$ as follows:

$$
V d_{h}=\sum_{l=1}^{m} \sum_{p o=1}^{2}\left(w_{l, p o} \times\left(V d_{l, p o}\right)^{h}\right), \quad h=1,2,
$$

where $V d_{h}$ is the $h$ th moment of Objective 2. The total voltage deviation (Eq. (3)) was calculated for every uncertain set with fixed deterministic numbers following the procedure, as presented in Eq. (43). Thus, $V d_{l, p o}$ can be expressed as follows:

$$
\begin{aligned}
& V d_{l, p o}=f\left(D_{v}, \mu_{R_{1}}, \mu_{R_{2}}, \cdots, z_{l, p o}, \cdots, \mu_{R_{m}}\right), \\
& p o=1,2 ; \quad l=1,2,3, \cdots, m .
\end{aligned}
$$

\subsubsection{Modification of Objective Functions $3 \& 4$}

Objectives 3 (weightage) and 4 (cost) do not depend on the uncertainties but rather on only deterministic variables, i.e., locations of the EVCS in this work. The objective functions, $f_{33}$ and $f_{44}$, can be written as follows:

$$
\begin{aligned}
& \max \left(f_{33}\right)=\max \left(f_{3}\right), \\
& \min \left(f_{44}\right)=\min \left(f_{4}\right),
\end{aligned}
$$

where weightage and cost were set as maximization and minimization problems, respectively.

\subsection{2-layer optimization to solve the proposed problem}

2-layer optimization [81] was formed in this work to solve the problem of EVCS and DG allocation by DE and HHO techniques. The upper layer was formed with the EVCS allocation model including four objective functions (Eq. (35)). The lower layer was modeled for DG allocation with two objective functions (Eq. (36)). The optimization techniques adopted to solve the above-mentioned problems are presented below.

\subsubsection{Differential Evolution (DE) [72]}

DE is an old optimization method based on evolutionary method. In 1997, Storn ad Price developed DE [72]. The main steps can be explained below and additional methodologies were mentioned in [72]:

i. Population creation: Initialization of the deterministic variable can be performed by:

$$
\begin{aligned}
& K_{i j}=K_{j}^{\min }+\operatorname{rand} \times\left(K_{j}^{\max }-K_{j}^{\min }\right), \text { where: } \\
& i=1,2,3 \cdots, S_{p} ; \quad j=1,2,3 \cdots, D_{n},
\end{aligned}
$$

where $K_{i j}$ is the random decision variable; $S_{p}$ is the population size; $D_{n}$ is number of decision variable; $K_{j}^{\max }$ is the maximum limit; and $K_{j}^{\mathrm{min}}$ is the minimum limit.

ii. Mutation with Strategy 1: A mutated vector $M_{i}^{(Z)}$ is produced by mutation operator as follows:

$$
M_{i}^{(Z)}=K_{m 1}^{(Z)}+F \cdot\left(K_{m 2}^{(Z)}-K_{m 3}^{(Z)}\right)
$$

where $m 1, m 2$, and $m 3$ are random positions of $K$ vector. $F \in[0,2]$ is the scaling factor.

iii. Crossover: A new trial vector $C O_{i j}^{(Z+1)}$ is produced by mixing the parent vector $\left(K_{i}^{(Z)}\right)$ with mutated vector $M_{i}^{(Z)}$ as follows:

$$
C O_{i j}^{(Z+1)}= \begin{cases}M_{i j}^{(Z)}, & \text { if } \text { rand } j<C R \text { or } j=q \\ K_{i j}^{(Z)}, & \text { otherwise }\end{cases}
$$

$C R$ is the crossover rate $\in[0,1]$, and $q$ is a random number $\in\left[0, D_{n}\right]$. 
iv. Selection: The best vector between the trial vector and the updated parent vector is selected based on the objective function value as follows:

$$
K_{i}^{(Z+1)}= \begin{cases}C O_{i}^{(Z)}, & \text { if } f\left(C O_{i}^{(Z)}\right) \leq f\left(K_{i}^{(Z)}\right) \\ K_{i}^{(Z)}, & \text { otherwise }\end{cases}
$$

\subsubsection{Harris Hawks Optimization (HHO) [74]}

Mathematical model of Harris' hawks hunting strategy is used in this technique, where Harris' hawks chase the rabbit. The main steps are explained below and additional methodologies were mentioned in [74]:

i. Population creation: Initialization of the deterministic variables $\left(K_{i j}\right)$ can be performed by:

$$
\begin{aligned}
& K_{i j}=K_{j}^{\min }+\operatorname{rand} \times\left(K_{j}^{\max }-K_{j}^{\min }\right), \text { where: } \\
& i=1,2,3, \cdots, S_{p} ; \quad j=1,2,3, \ldots, D_{n} .
\end{aligned}
$$

Initialize the preliminary energy $\left(E n_{0}\right)$ and jump strength $(J s)$ as follows:

$$
\begin{aligned}
& E n_{0}=2 \times \operatorname{rand}(-1,1)-1, \\
& J s=2 \times(1-\operatorname{rand}(0,1)) .
\end{aligned}
$$

ii. Update part: Update energy $(E n)$ at every iteration using:

$$
E n=2 \times E n_{0}\left(1-\frac{t}{T}\right)
$$

where $t$ is the present iteration and $T$ is total iteration. The vector of decision variable $\left(K^{(Z+1)}\right)$ is updated as follows:

- Exploration phase (if $|E n| \geq 1$ ):

$$
\begin{aligned}
& K^{(Z+1)} \\
& =\left\{\begin{array}{l}
K_{\text {rand }}^{(Z)}-m_{1}\left|K_{\text {rand }}^{(Z)}-2 m_{2} K^{(Z)}\right| \\
\quad \text { if } q \geq 0.5 \\
\\
K_{\text {rabbit }}^{(Z)}-K_{m}^{(Z)}-m_{3}\left(L L+m_{4}(U L-L L)\right) \\
\text { if } q<0
\end{array}\right.
\end{aligned}
$$

where $Z$ is iteration number, $K_{\text {rabbit }}^{(Z)}$ the position of the rabbit, and $K_{\text {rand }}^{(Z)}$ randomly selected hawk position. $m_{1}, m_{2}, m_{3}, m_{4}$, and $q$ are random numbers $\in[0,1]$. $U L$ is the upper limit while $L L$ is the lower limit.

- Exploitation phase (if $|\boldsymbol{E n}|<\mathbf{1}$ ): $r$ is the chance for a rabbit to escape.

Based on the values of $r$ and $E n$, exploitation phase consists following categories:
- Soft besiege (if $r \geq 0.5$ and $|E n| \geq$ $0.5)$ :

$$
\begin{aligned}
& K^{(Z+1)}=\Delta K^{(Z)}-E\left|J s \times K_{\text {rabbit }}^{(Z)}-K^{(Z)}\right|, \\
& \Delta K^{(Z)}=K_{\text {rabbit }}^{(Z)}-K^{(Z)} .
\end{aligned}
$$

- Hard besiege (if $r \geq 0.5$ and $|E n|<$ $0.5)$ :

$$
K^{(Z+1)}=K_{\text {rabbit }}^{(Z)}-E\left|\Delta K^{(Z)}\right| .
$$

- Soft besiege with progressive rapid dives (if $r<0.5$ and $|E n| \geq 0.5$ ):

$$
\begin{aligned}
& K^{(Z+1)}= \begin{cases}A, & \text { if } F(A)<F\left(K^{(Z)}\right) \\
B, & \text { if } F(B)<F\left(K^{(Z)}\right)\end{cases} \\
& A=K_{\text {rabbit }}^{(Z)}-E\left|J s \times K_{\text {rabbit }}^{(Z)}-K^{(Z)}\right|, \\
& B=A+S+L F(D),
\end{aligned}
$$

where $S$ is random vector $(1 \times D)$; $D$ is the dimension of the problem; and $L F$ is the levy flight function [74].

- Hard besiege with progressive rapid dives (if $r<0.5$ and $|E n|<0.5$ ):

$$
\begin{aligned}
& K^{(Z+1)}= \begin{cases}A, & \text { if } F(A)<F\left(K^{(Z)}\right) \\
B, & \text { if } F(B)<F\left(K^{(Z)}\right)\end{cases} \\
& A=K_{\text {rabbit }}^{(Z)}-E\left|J s \times K_{\text {rabbit }}^{(Z)}-K_{m}^{(Z)}\right|,
\end{aligned}
$$

where $K_{m}^{(Z)}$ is the average position of hawk as calculated below:

$$
K_{m}^{(Z)}=\frac{1}{H n} \sum_{i=1}^{H n} K_{i}^{(Z)}
$$

where $H n$ is the total number of hawks.

$$
B=A+S+L F(D) \text {. }
$$

\subsubsection{2-layer optimization}

The flowchart of the 2-layer optimization for this work using DE \& HHO is presented in Figure 1.

\subsection{Best non-dominated solution [82,83]}

\subsubsection{Pareto solution}

The multi-objective function was transformed into a single-objective one with different weighting coefficients. Some objectives are in conflict while solving the optimization problem. The Pareto optimal sets were formed with the combinations of $\omega_{1}, \omega_{2}, \omega_{3}$, and $\omega_{4}$. Moreover, $\omega_{1}, \omega_{2}, \omega_{3}$ vary from 0 to 1 at a step of 0.05 and $\omega_{4}$ is $\left(1-\omega_{1}-\omega_{2}-\omega_{3}, \omega_{4} \geq 0\right)$. At last, based on the fuzzy set theory, the best solution was selected from Pareto optimal solutions. 


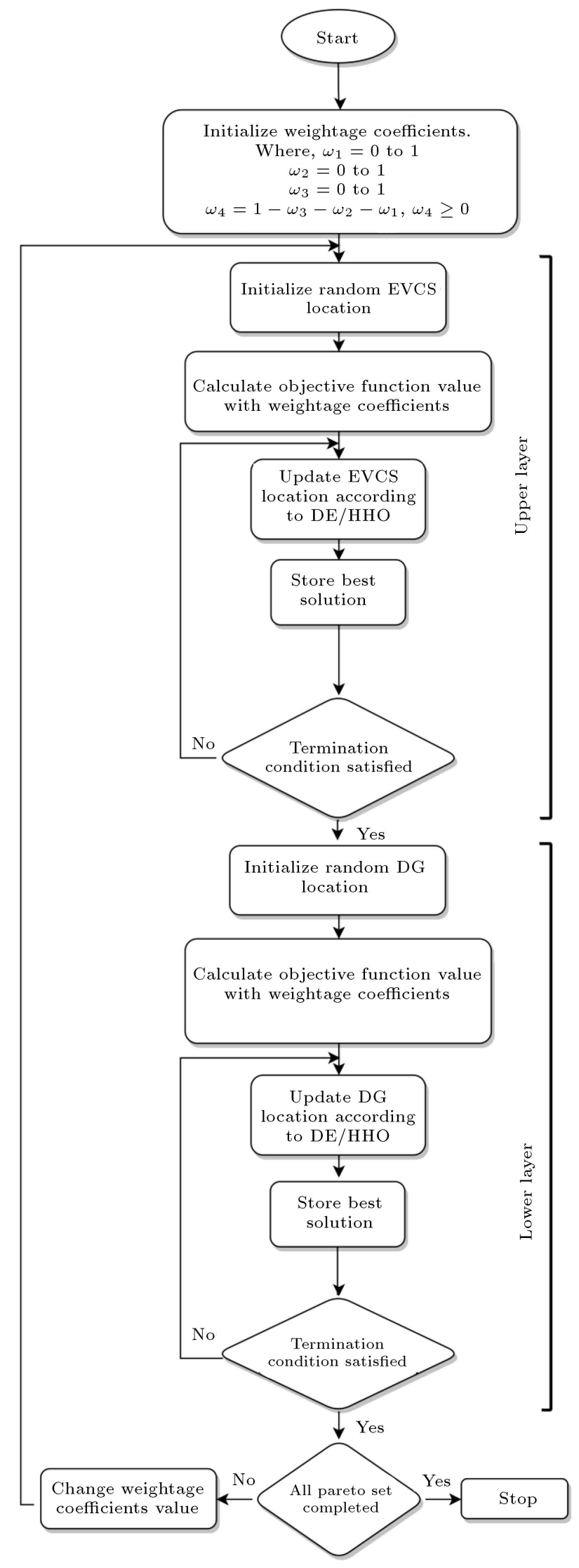

Figure 1. Flowchart of the 2-layer optimization for the present work.
3.6.2. Selection of the best non-dominated solution Interactive fuzzy satisfying method $[82,83]$ was employed to achieve an acceptable solution from Pareto optimal sets:

$$
\mu f_{i i}= \begin{cases}\text { if maximization: } & \\ 1, & f_{i i} \leq f_{i i}^{\min } \\ \frac{f_{i i}-f_{i i}^{\min }}{f_{i i}^{\max }-f_{i i}^{\min }}, & f_{i i}^{\min }<f_{i i}<f_{i i}^{\max } \\ \text { if minimization: } & \\ \frac{f_{i i}^{\max }-f_{i i}}{f_{i i}^{\max }-f_{i i}^{\min }}, & f_{i i}^{\min }<f_{i i}<f_{i i}^{\max } \\ 0, & f_{i i} \geq f_{i i}^{\max }\end{cases}
$$

where $\mu f_{i i}$ is the membership function value of the modified $i$ th objective function. $\mu f_{i i}$ creates the nondominated sets. The usefulness of all the sets was determined in terms of normalized values obtained in $[75]$ :

$$
\mu_{n m}^{n d}=\frac{\sum_{i=1}^{N_{o b}} \mu^{n d} f_{i i}}{\sum_{n d}^{N_{n d}} \sum_{i=1}^{N_{o b}} \mu^{n d} f_{i i}},
$$

where $\mu_{n m}^{n d}$ is the normalized membership value of the $n d$ th non-dominated set. $N_{n d}$ and $N_{o b}$ are the number of non-dominated sets and the number of objective functions, respectively. The best non-dominated set is having the maximum normalized membership value, i.e., $\max \left(\mu_{n m}^{n d} ; n d=1,2, \cdots, N_{n d}\right)$.

\section{Simulation study and results}

\subsection{Network data}

A superimposed system with a distribution network and a road network is taken in this work [75]. A 33node radial network was considered as the distribution system [84]; node 1 is the substation. The road network with the distribution system is shown in Figure 2.

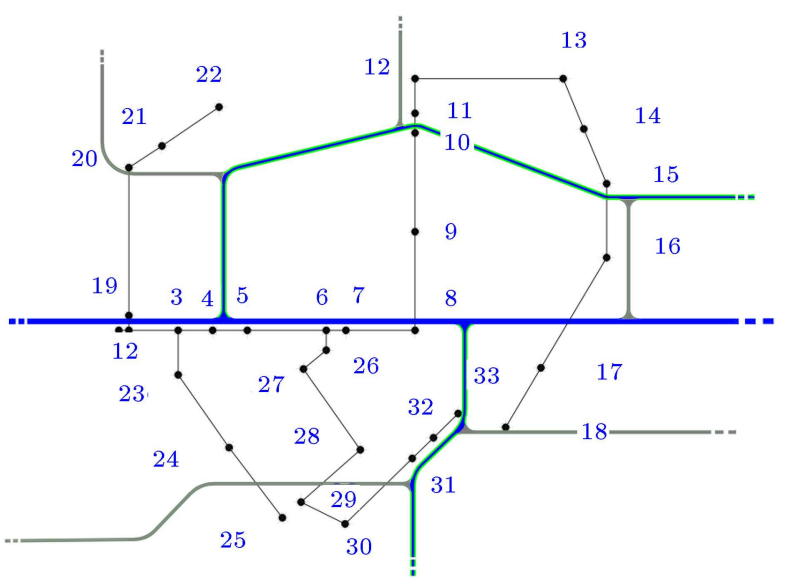

Figure 2. The urban study area with a distribution system [75]. 
Table 2. Input data of vehicles used for present study [75].

\begin{tabular}{ccccc}
\hline $\begin{array}{c}\text { EV } \\
\text { type }\end{array}$ & $\begin{array}{c}\text { Battery capacity } \\
(\mathbf{k W h})\end{array}$ & $\begin{array}{c}\text { All Electric Range (AER) } \\
(\mathbf{k m})\end{array}$ & $\begin{array}{c}\text { Battery } \\
\text { type }\end{array}$ & $\begin{array}{c}\text { Existing in the area } \\
(\mathbf{\%})\end{array}$ \\
\hline I & 13.8 & 48.27 & Li-ion & 60 \\
II & 18.4 & 64.36 & Li-ion & 30 \\
III & 24 & 117 & Li-ion & 10 \\
\hline
\end{tabular}

Table 3. Fast-charging station placement for Case 1 with $100 \%$ electric vehicle penetration.

\begin{tabular}{|c|c|c|c|c|c|c|c|}
\hline \multirow{2}{*}{ Technique } & \multirow{2}{*}{\multicolumn{3}{|c|}{$\begin{array}{c}\text { EVCS } \\
\text { locations }\end{array}$}} & \multicolumn{2}{|c|}{ Energy loss (kWh) } & \multicolumn{2}{|c|}{ Voltage deviation } \\
\hline & & & & Mean & SD & Mean & SD \\
\hline $\mathrm{DE}$ & 2 & 19 & 20 & 5162.8797 & 0.25354 & 43.5264 & 0.00000032452 \\
\hline HHO & 2 & 19 & 20 & 5162.873506 & 0.256548 & 43.5264561 & 0.000000323021 \\
\hline
\end{tabular}

Three main roads were taken: the blue road with the highest number of vehicles; green road with a moderate number of vehicles; and ash color road with the smallest number of vehicles.

\section{2. $E V$ and $C S$ data}

200 EVs were taken and 3 EVCSs were allocated in the study area. In a city, there are various types of EV present with different battery capacities and mileage. Hence, three EV types were taken into consideration. Their battery capacities, battery types, all-electric ranges, and percentage of presence in the area are shown in Table 2 [77]. Type-I and type-II belong to PHEV, and type-III is the pure battery EV.

In this work, fast-charging facilities have only been considered with the charging and discharging rates of $19 \mathrm{~kW}$ and $8 \mathrm{~kW}[41,85]$ with efficiencies of $95 \%$ and $80 \%[86,87]$ for $\mathrm{G} 2 \mathrm{~V}$ and $\mathrm{V} 2 \mathrm{G}$, respectively.

\subsection{Input data for Solar $D G$}

Peak capacity of $10.46 \mathrm{~kW}$ for three solar DG units with 200 panels was allocated (other data were taken from [80]).

\subsection{Result and discussion}

The problem was modeled in MATLAB programming on a computer with $8 \mathrm{~GB}$ ram. Optimizations were performed for different population and iterations. It was observed that 30 population and 100 iterations solved the present problem with a shorter amount of time and provided optimized results for both optimization techniques.

Eight case studies have targeted the best nondominated solution. Case 1 is a case that does not consider the road network and zone constraint. Cases 2-7 consider the distribution system along with the road system with the zone constraint of the urban area:

- Case 1: Energy loss minimization (placement of EVCS only in distribution systems);
- Case 2: Energy loss minimization;

- Case 3: Cost minimization;

- Case 4: Energy loss and cost minimization;

- Case 5: Energy loss, voltage deviation, and cost minimization;

- Case 6: Energy loss, voltage deviation, and cost minimization with weightage maximization;

- Case 7: Simultaneous allocation of EVCS and DG considering energy loss minimization, voltage deviation minimization, land cost minimization, and weightage maximization.

First, Case 1 to Case 6 were considered for the worst case (100\% EV penetration). Finally, Cases 6 and 7 were considered for different penetration levels of $\mathrm{EV}$.

\subsubsection{Single-objective solutions}

Case 1 to Case 3 were performed considering different single objective function, as follows:

- Case 1: In this case, the energy loss was minimized by optimally placing the EVCS considering only distribution network without zone constraint. Table 3 presents the optimal nodes for the EVCS using DE and HHO. Figure 3 shows the convergence of DE and HHO. The voltage profile of the distribution

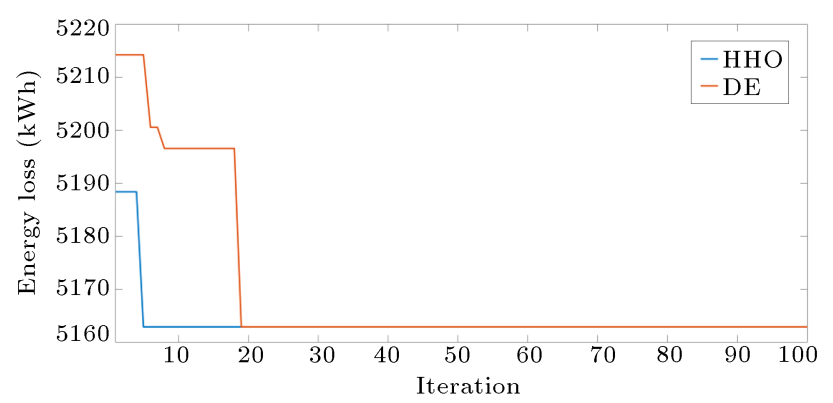

Figure 3. Convergence curves of Differential Evolution (DE) and Harris Hawks Optimization (HHO) for Case 1 with $100 \%$ Electric Vehicle (EV) penetration. 


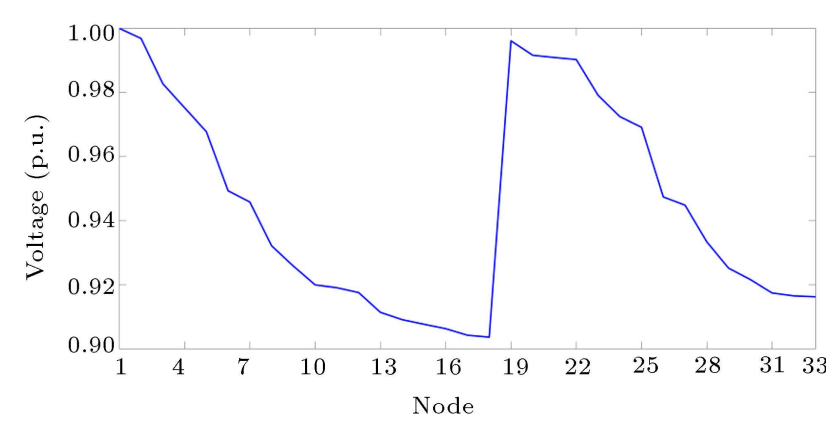

Figure 4. Voltage profile of the distribution network for Case 1 with $100 \%$ electric vehicle penetration.

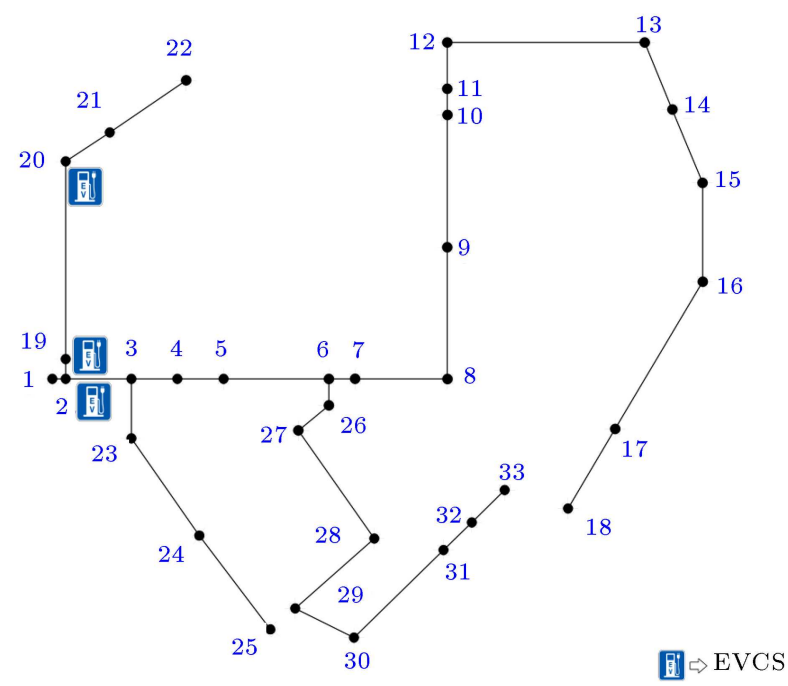

Figure 5. Optimized electric vehicle charging station locations in only distribution networks without zone division [75].

system after allocating the EVCS is presented in Figure 4.

To minimize the energy loss, EVCSs were allocated to nodes 2, 19, and 20. According to Figure 5, the EVCS locations are adjacent to each other and a large area is not fit to getting the availability of the CS;

- Case 2: EVs need more SOC to travel up to a distant EVCS. Moreover, more than one EVCS is not preferable in a particular location. Distributed EVCSs can serve all users in a better manner in the urban area. Hence, EVCS should be placed in each zone for better accessibility to all users. Therefore, the entire study area was divided into 3 zones on the basis of zone-wise EV density and charging demand. Figure 6 shows the zone divisions in the urban area.

Land cost is an important factor in terms of establishment cost of the EVCS in a location in the road network. Considering the important locations in the area, the node-wise land costs for EVCS were considered. The land costs are shown in Table 4 based on the aforementioned assumption. However,

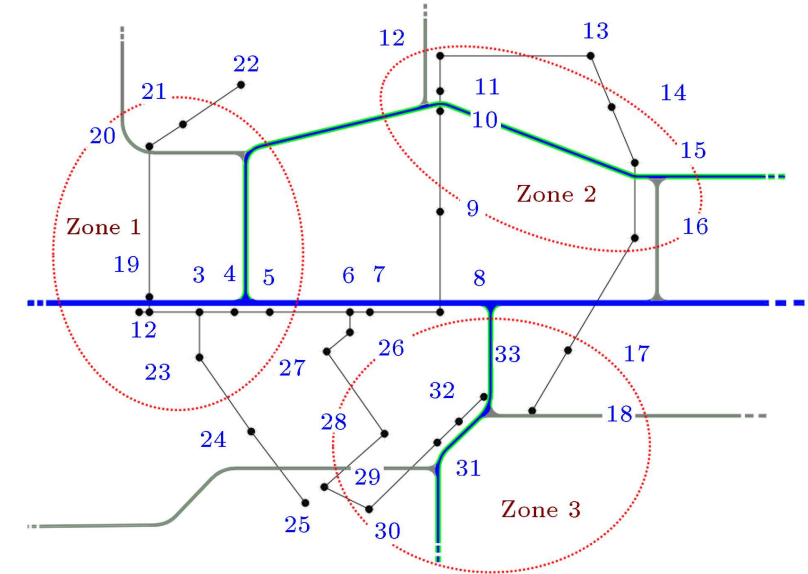

Figure 6. Superimposed network of the road and distribution system with 3 zones [75].

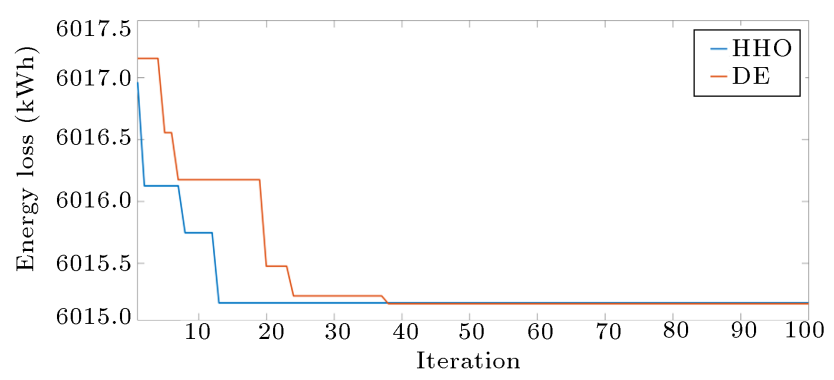

Figure 7. Convergence curves of Harris hawks optimization and differential evolution for Case 2 with $100 \%$ electric vehicle penetration.

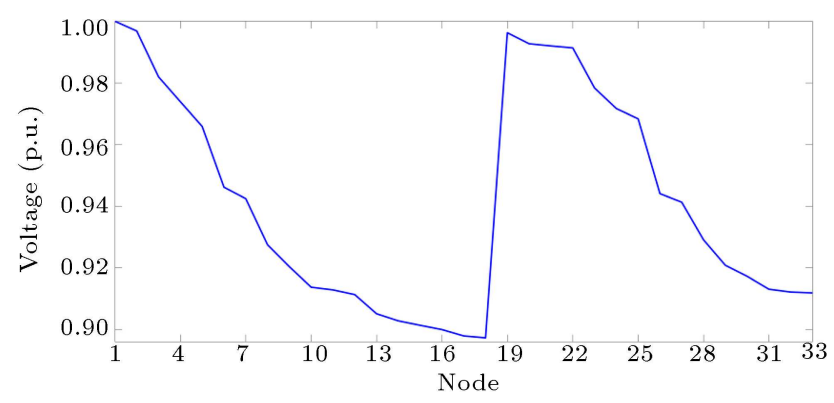

Figure 8. Voltage profile of the distribution network for Case 2 with $100 \%$ electric vehicle penetration.

minimization of land cost may offer a biased solution with important locations. For instance, optimal locations of EVCS may be low-cost lands where vehicle density may not be high. To solve this issue, weightages were assigned to all the nodes in Table 4 depending on density of the EV.

Table 5 shows the optimal results for Case 2 . Locations 2, 10, and 28 are the optimal places for EVCS. These locations are distributed in the area. Case 2 provides the second minimum energy loss, but land cost is maximum and weightage is not maximum. The convergence curves of DE and HHO are presented in Figure 7. Figure 8 shows the voltage profile of the system; 
Table 4. Land cost and weightage of the nodes [75].

\begin{tabular}{|c|c|c|c|c|c|c|c|c|}
\hline Node & $\begin{array}{c}\text { Weightage } \\
\qquad\left(w_{S}\right)\end{array}$ & $\begin{array}{c}\text { Cost }(\$) \\
\left(c_{S}\right)\end{array}$ & Node & $\begin{array}{c}\text { Weightage } \\
\left(w_{S}\right)\end{array}$ & $\begin{array}{c}\text { Cost }(\$) \\
\left(c_{S}\right)\end{array}$ & Node & $\begin{array}{c}\text { Weightage } \\
\left(w_{S}\right)\end{array}$ & $\begin{array}{c}\text { Cost }(\$) \\
\left(c_{S}\right)\end{array}$ \\
\hline 1 & 0 & 55270.6 & 12 & 1 & 52421.6 & 23 & 0.9 & 45584 \\
\hline 2 & 0.5 & 56410.2 & 13 & 0 & 43874.6 & 24 & 0 & 40455.8 \\
\hline 3 & 1 & 55840.4 & 14 & 0.2 & 45014.2 & 25 & 0 & 38746.4 \\
\hline 4 & 1 & 56980 & 15 & 0.6 & 50142.4 & 26 & 0 & 52421.6 \\
\hline 5 & 1 & 55270.6 & 16 & 0.5 & 46153.8 & 27 & 0 & 51282 \\
\hline 6 & 0 & 35327.6 & 17 & 0.3 & 37037 & 28 & 0.6 & 42735 \\
\hline 7 & 0 & 54700.8 & 18 & 1 & 56410.2 & 29 & 0 & 39316.2 \\
\hline 8 & 0 & 55840.4 & 19 & 0.5 & 55840.4 & 30 & 0.4 & 41025.6 \\
\hline 9 & 0 & 33048.4 & 20 & 0.4 & 48433 & 31 & 1 & 50712.2 \\
\hline 10 & 1 & 54700.8 & 21 & 0.3 & 44444.4 & 32 & 1 & 49572.6 \\
\hline 11 & 1 & 54700.8 & 22 & 0 & 42735 & 33 & 0.6 & 46153.8 \\
\hline
\end{tabular}

Table 5. Fast-charging station placement for Case 2 with $100 \%$ electric vehicle penetration.

\begin{tabular}{|c|c|c|c|c|c|c|c|c|c|}
\hline \multirow{2}{*}{ Technique } & \multirow{2}{*}{\multicolumn{3}{|c|}{$\begin{array}{c}\text { EVCS } \\
\text { locations }\end{array}$}} & \multicolumn{2}{|c|}{ Energy loss (kWh) } & \multicolumn{2}{|c|}{ Voltage deviation } & \multirow{2}{*}{$\begin{array}{c}\text { Total cost } \\
(\$)\end{array}$} & \multirow{2}{*}{$\begin{array}{c}\text { Total } \\
\text { weightage }\end{array}$} \\
\hline & & & & Mean & SD & Mean & SD & & \\
\hline $\mathrm{DE}$ & 2 & 10 & 28 & 6015.1734 & 26.5182 & 46.1396 & 0.0001100 & 153846 & 2.1 \\
\hline HHO & 2 & 10 & 28 & 6015.1802 & 22.3668 & 46.140108 & 0.0000862132 & 153846 & 2.1 \\
\hline
\end{tabular}

Table 6. Fast-charging station placement for Case 3 with $100 \%$ electric vehicle penetration.

\begin{tabular}{|c|c|c|c|c|c|c|c|}
\hline \multirow{2}{*}{ Technique } & \multirow{2}{*}{$\begin{array}{c}\text { EVCS } \\
\text { locations }\end{array}$} & \multicolumn{2}{|c|}{ Energy loss (kWh) } & \multicolumn{2}{|c|}{ Voltage deviation } & \multirow{2}{*}{$\begin{array}{c}\text { Total cost } \\
(\$)\end{array}$} & \multirow{2}{*}{$\begin{array}{c}\text { Total } \\
\text { weightage }\end{array}$} \\
\hline & & Mean & SD & Mean & SD & & \\
\hline $\mathrm{DE}$ & $\begin{array}{lll}21 & 14 & 17\end{array}$ & 7727.5715 & 67.511758 & 49.067329 & 0.00113457442 & 126495.6 & 0.8 \\
\hline HHO & $21 \quad 14 \quad 17$ & 7728.25103 & 63.9086479 & 49.0682681 & 0.00103093378 & 126495.6 & 0.8 \\
\hline
\end{tabular}

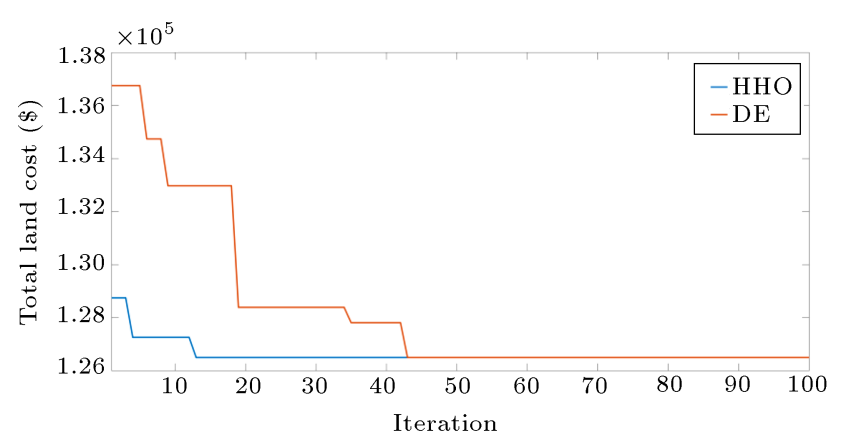

Figure 9. Convergence curve of Harris hawks optimization for Case 3 with $100 \%$ electric vehicle penetration.

- Case 3: In this case, land cost was considered as the objective function and was reduced after optimal placement of EVCS. 21, 14, and 17 were the optimal places to achieve minimum cost, as presented in Table 6. Figure 9 presents the convergence curves of $\mathrm{DE}$ and HHO. Voltage profile is shown in Figure 10, which is not in acceptable limits. Therefore, if only cost is considered, then it is minimum while weightage is quite low. It is implied that the

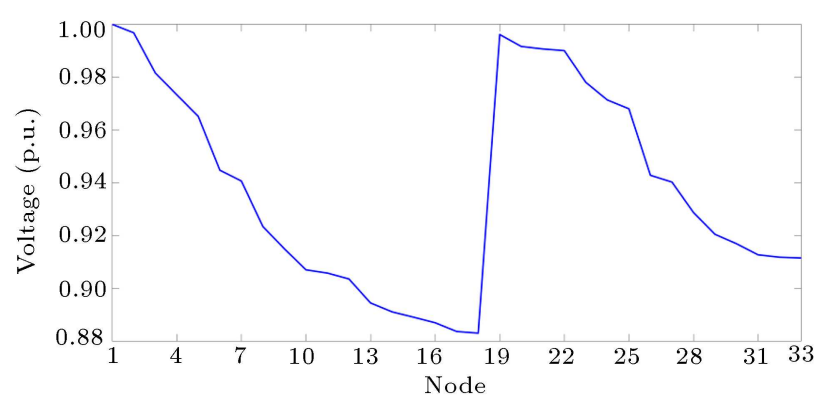

Figure 10. Voltage profile of distribution network for Case 3 with $100 \%$ electric vehicle penetration.

locations would not be able to serve the EVs in vital places in urban areas. Moreover, energy loss and voltage deviation are maximum as compared to other cases.

\subsubsection{Multi-objective solutions}

Case 4 to Case 7 were performed considering different combinations of multiple objective functions, as follows:

- Case 4: The application of a single-objective solution is not sufficient for proper allocation. In this 
Table 7. Fast-charging station placement for Case 4 with $100 \%$ electric vehicle penetration.

\begin{tabular}{|c|c|c|c|c|c|c|c|c|c|}
\hline \multirow{3}{*}{$\begin{array}{c}\text { Technique } \\
\text { DE }\end{array}$} & \multirow{2}{*}{\multicolumn{3}{|c|}{$\begin{array}{c}\text { EVCS } \\
\text { locations }\end{array}$}} & \multicolumn{2}{|c|}{ Energy loss (kWh) } & \multicolumn{2}{|c|}{ Voltage deviation } & \multirow{3}{*}{$\begin{array}{c}\text { Total cost } \\
(\$) \\
132193.6\end{array}$} & \multirow{3}{*}{$\begin{array}{c}\begin{array}{c}\text { Total } \\
\text { weightage }\end{array} \\
1.1\end{array}$} \\
\hline & & & & \multirow{2}{*}{$\begin{array}{c}\text { Mean } \\
6239.9966\end{array}$} & \multirow{2}{*}{$\begin{array}{c}\text { SD } \\
44.167678\end{array}$} & \multirow{2}{*}{$\begin{array}{c}\text { Mean } \\
46.66619\end{array}$} & \multirow{2}{*}{$\begin{array}{c}\text { SD } \\
0.00016235083\end{array}$} & & \\
\hline & 21 & 14 & 28 & & & & & & \\
\hline НHO & 21 & 14 & 28 & 6239.9344 & 40.9679449 & 46.666158 & 0.00014489954 & 132193.6 & 1.1 \\
\hline
\end{tabular}

Table 8. Fast-charging station placement for Case 5 with $100 \%$ electric vehicle penetration.

\begin{tabular}{|c|c|c|c|c|c|c|c|c|c|}
\hline \multirow{3}{*}{$\begin{array}{c}\text { Technique } \\
\text { DE }\end{array}$} & \multirow{2}{*}{\multicolumn{3}{|c|}{$\begin{array}{c}\text { EVCS } \\
\text { locations }\end{array}$}} & \multicolumn{2}{|c|}{ Energy loss (kWh) } & \multicolumn{2}{|c|}{ Voltage deviation } & \multirow{3}{*}{$\begin{array}{c}\text { Total cost } \\
(\$) \\
141880.2\end{array}$} & \multirow{3}{*}{$\begin{array}{c}\begin{array}{c}\text { Total } \\
\text { weightage }\end{array} \\
1.9\end{array}$} \\
\hline & & & & \multirow{2}{*}{$\begin{array}{c}\text { Mean } \\
6067.77918\end{array}$} & \multirow{2}{*}{$\frac{\text { SD }}{21.10324}$} & \multirow{2}{*}{$\begin{array}{c}\text { Mean } \\
46.230524\end{array}$} & \multirow{2}{*}{$\begin{array}{c}\text { SD } \\
0.0000812366295\end{array}$} & & \\
\hline & 21 & 10 & 28 & & & & & & \\
\hline $\mathrm{HHO}$ & 21 & 10 & 28 & 6067.58919 & 26.125667 & 46.230191 & 0.0001068152065 & 141880.2 & 1.9 \\
\hline
\end{tabular}

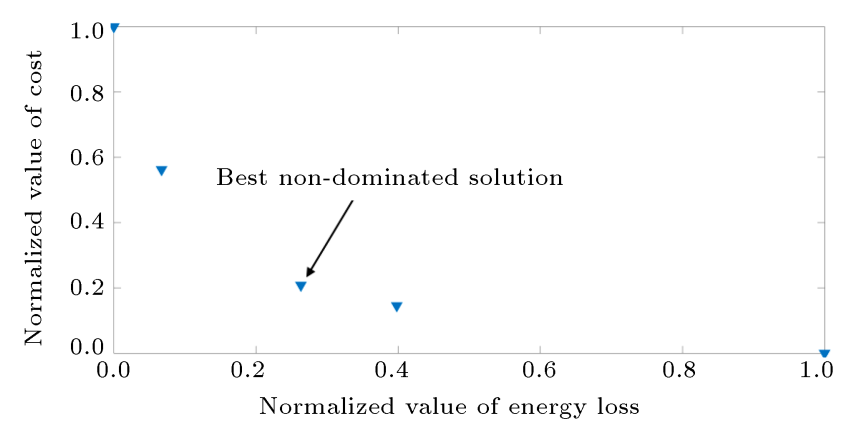

Figure 11. Pareto plot of Case 4.

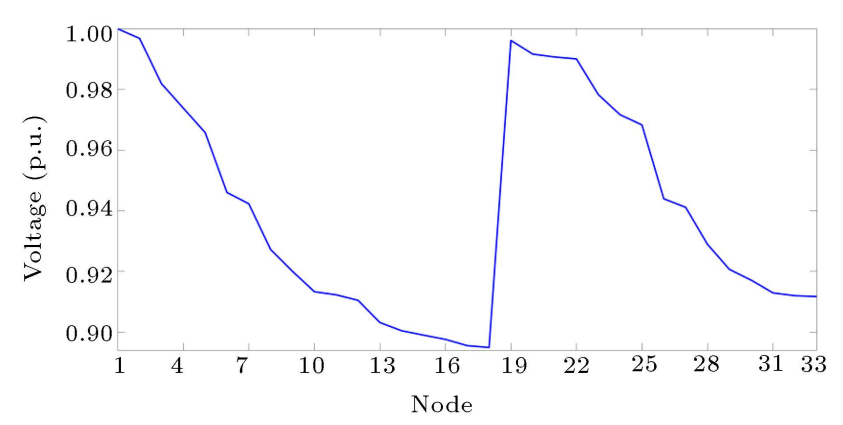

Figure 12. Voltage profile of distribution system for Case 4 with $100 \%$ electric vehicle penetration.

case, energy loss and cost are considered. Table 7 presents the optimal results for Case 4 . The optimal EVCS locations are 21, 14, and 28 that differ from those in the previous cases. Pareto plot for Case 4 is displayed in Figure 11, as Cases 4-7 are multiobjective problems. Voltage profile is shown in Figure 12. Case 4 provides a moderate solution for energy loss and cost while weightage is not high;

- Case 5: Only energy loss and cost consideration will not be sufficient because the customers of all nodes should not suffer from voltage dip. Hence, voltage deviation was minimized in this case following energy loss and cost minimization.

According to Table 8 , the optimal nodes are 21,10 , and 28 , which are not the same as those

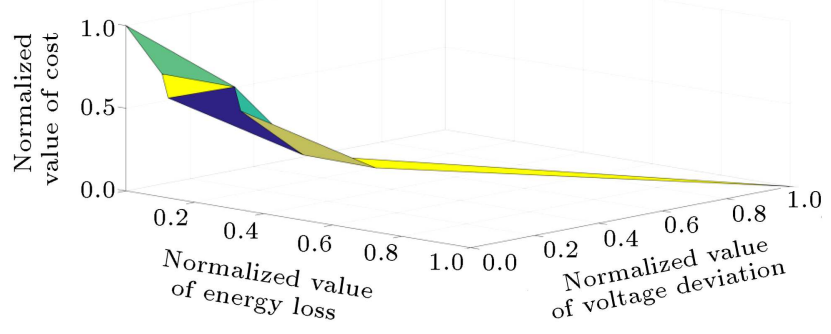

Figure 13. Pareto plot of Case 5.

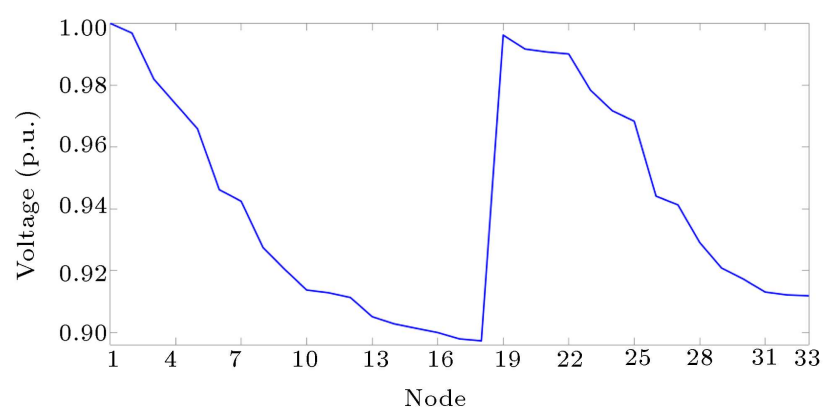

Figure 14. Voltage profile of distribution network for Case 5 with $100 \%$ electric vehicle penetration.

in Case 4. Voltage deviation was reduced to a greater degree than that in the previous case while weightage might increase. Figures 13 and 14 present the Pareto plot and voltage profile, respectively;

- Case 6: In this case, weightage maximization is taken simultaneously with other objectives to cover the vital places where charging demand is high.

Table 9 presents the optimal solutions by DE and HHO. The locations are changed to 10, 23, and 28 to maximize the weightage with other objectives. A balanced optimal solution was obtained for all aspects with high weightage and minimum energy loss, voltage deviation, and land cost. Voltage profile of the system is shown in Figure 15. Previous cases were solved for worst penetration of $\mathrm{EV}$, but EV penetration was not fixed. Hence, Table 10 
Table 9. Fast-charging station placement for Case 6 with $100 \%$ electric vehicle penetration.

\begin{tabular}{|c|c|c|c|c|c|c|c|c|c|}
\hline \multirow{3}{*}{$\begin{array}{c}\text { Technique } \\
\text { DE }\end{array}$} & \multirow{2}{*}{\multicolumn{3}{|c|}{$\begin{array}{c}\text { EVCS } \\
\text { locations }\end{array}$}} & \multicolumn{2}{|c|}{ Energy loss (kWh) } & \multicolumn{2}{|c|}{ Voltage deviation } & \multirow{3}{*}{$\begin{array}{c}\text { Total cost } \\
(\$) \\
143019.8\end{array}$} & \multirow{3}{*}{$\begin{array}{c}\begin{array}{c}\text { Total } \\
\text { weightage }\end{array} \\
2.5\end{array}$} \\
\hline & & & & \multirow{2}{*}{$\begin{array}{c}\text { Mean } \\
6151.2632\end{array}$} & \multirow{2}{*}{$\begin{array}{c}\text { SD } \\
26.0774\end{array}$} & \multirow{2}{*}{$\begin{array}{c}\text { Mean } \\
46.3933\end{array}$} & \multirow{2}{*}{$\begin{array}{c}\text { SD } \\
0.000094732\end{array}$} & & \\
\hline & 10 & 23 & 28 & & & & & & \\
\hline НHO & 10 & 23 & 28 & 6151.58608 & 23.24655 & 46.39395 & 0.000082266 & 143019.8 & 2.5 \\
\hline
\end{tabular}

Table 10. Fast-charging station placement for Case 6 with different electric vehicle penetrations.

\begin{tabular}{|c|c|c|c|c|c|c|c|c|c|c|}
\hline \multirow{2}{*}{ Technique } & \multirow{2}{*}{$\begin{array}{c}\text { EV } \\
\text { penetration }(\%)\end{array}$} & \multirow{2}{*}{\multicolumn{3}{|c|}{$\begin{array}{c}\text { EVCS } \\
\text { locations }\end{array}$}} & \multicolumn{2}{|c|}{ Energy loss (kWh) } & \multicolumn{2}{|c|}{ Voltage deviation } & \multirow{2}{*}{$\begin{array}{c}\text { Total cost } \\
(\$)\end{array}$} & \multirow{2}{*}{$\begin{array}{c}\text { Total } \\
\text { weightage }\end{array}$} \\
\hline & & & & & Mean & SD & Mean & SD & & \\
\hline $\mathrm{DE}$ & $15[75]$ & 28 & 23 & 10 & 5158.9586 & 2.9962 & 43.7076 & 0.0000480 & 143019.8 & 2.5 \\
\hline $\mathrm{HHO}$ & $15[75]$ & 28 & 23 & 10 & 5159.0246 & 2.9719 & 43.7078 & 0.0000464 & 143019.8 & 2.5 \\
\hline $\mathrm{DE}$ & $30[75]$ & 28 & 23 & 10 & 5272.4571 & 4.5182 & 44.1236 & 0.0000518 & 143019.8 & 2.5 \\
\hline $\mathrm{HHO}$ & $30[75]$ & 28 & 23 & 10 & 5272.5450 & 3.26902 & 44.1240 & 0.0000355 & 143019.8 & 2.5 \\
\hline $\mathrm{DE}$ & $45[75]$ & 28 & 23 & 10 & 5404.4065 & 8.0595 & 44.5499 & 0.0000745 & 143019.8 & 2.5 \\
\hline $\mathrm{HHO}$ & $45[75]$ & 28 & 23 & 10 & 5404.5905 & 6.64002 & 44.5505 & 0.0000578 & 143019.8 & 2.5 \\
\hline $\mathrm{DE}$ & $60[75]$ & 28 & 23 & 10 & 5556.8677 & 10.4186 & 44.9897 & 0.0000719 & 143019.8 & 2.5 \\
\hline HHO & $60[75]$ & 28 & 23 & 10 & 5556.9742 & 9.6702 & 44.9901 & 0.0000661 & 143019.8 & 2.5 \\
\hline $\mathrm{DE}$ & $75[75]$ & 28 & 23 & 10 & 5731.0482 & 13.1811 & 45.4428 & 0.0000707 & 143019.8 & 2.5 \\
\hline HHO & $75[75]$ & 28 & 23 & 10 & 5731.0935 & 12.8403 & 45.4431 & 0.0000687 & 143019.8 & 2.5 \\
\hline $\mathrm{DE}$ & $90[75]$ & 28 & 23 & 10 & 5928.2138 & 21.6032 & 45.9096 & 0.0001006 & 143019.8 & 2.5 \\
\hline НHO & $90[75]$ & 28 & 23 & 10 & 5928.4478 & 19.6242 & 45.9101 & 0.0000876 & 143019.8 & 2.5 \\
\hline $\mathrm{DE}$ & $100[75]$ & 28 & 23 & 10 & 6151.2632 & 26.0774 & 46.3933 & 0.0000947 & 143019.8 & 2.5 \\
\hline НHО & $100[75]$ & 28 & 23 & 10 & 6151.5860 & 23.2465 & 46.3939 & 0.0000822 & 143019.8 & 2.5 \\
\hline $\mathrm{DE}$ & 150 & 28 & 23 & 10 & 6785.2648 & 31.5789 & 49.4523 & 0.0001069 & 143019.8 & 2.5 \\
\hline $\mathrm{HHO}$ & 150 & 28 & 23 & 10 & 6785.1856 & 32.2569 & 49.4498 & 0.0001058 & 143019.8 & 2.5 \\
\hline
\end{tabular}

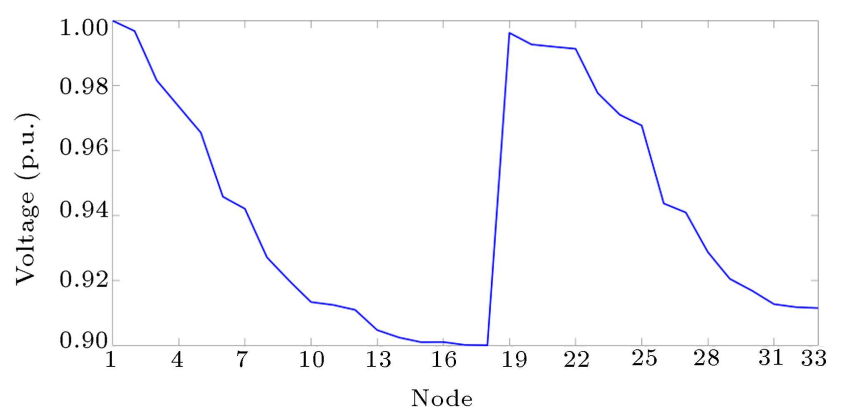

Figure 15. Voltage profile of distribution system for Case 6 with $100 \%$ electric vehicle penetration.

shows the optimal results for all EV penetration levels in Case 6 as the most feasible case.

It can be seen that the same locations, i.e., 10, 23 , and 28, are optimal for all the EV penetration levels. However, the energy loss and voltage deviation increased when the penetration level increased. It is the highest when EV penetration is $150 \%$. The energy loss and voltage deviation are provided in Table 10 with the total land cost and weightage;

- Case 7: In this case, EVCS and DG are allocated simultaneously using 2-layer optimization to reduce energy loss and voltage deviation. Table 11 presents the optimal places for both.

The same nodes 10, 23, and 28 were selected for the optimal EVCS location along with the optimal placement of solar DG on 16, 17, and 18. The energy loss and voltage deviation were reduced following the allocation of solar DGs.

\subsubsection{Comparison between Cases 6 and 7}

Case 6 and Case 7 were compared to analyse the contribution of the solar DG. The voltage profile improvement, energy loss and voltage deviation reduction due to the allocation of solar DG are discussed below:

- Voltage profile improvement: Simultaneous allocation of solar DG and EVCS in optimal places provides comparatively less energy loss and voltage deviation for every penetration levels. The voltage improvements achieved following the installation of solar DG in optimal places are given in Figures 16 and 17 to ensure minimum and maximum EV penetration levels, respectively;

- Energy loss and voltage deviation reduction: Figures 18 and 19 show the comparisons of energy 
Table 11. Fast-charging station placement for Case 7 with different levels of electric vehicle penetration with distributed generation.

\begin{tabular}{|c|c|c|c|c|c|c|c|c|c|c|c|}
\hline \multirow{3}{*}{$\frac{\text { Technique }}{\text { DE }}$} & \multirow{3}{*}{$\begin{array}{c}\text { EV penetration } \\
(\%)\end{array}$} & \multirow{2}{*}{\multicolumn{3}{|c|}{$\begin{array}{c}\text { EVCS } \\
\text { locations }\end{array}$}} & \multirow{2}{*}{\multicolumn{3}{|c|}{$\begin{array}{c}\text { DG } \\
\text { locations }\end{array}$}} & \multicolumn{2}{|c|}{ Energy loss (kWh) } & \multicolumn{2}{|c|}{ Voltage deviation } \\
\hline & & & & & & & & \multirow{2}{*}{$\begin{array}{c}\text { Mean } \\
5129.9440\end{array}$} & \multirow{2}{*}{$\frac{\text { SD }}{5.1807}$} & \multirow{2}{*}{$\begin{array}{c}\text { Mean } \\
43.5599\end{array}$} & \multirow{2}{*}{$\frac{\text { SD }}{0.000115}$} \\
\hline & & 28 & 23 & 10 & 16 & 17 & 18 & & & & \\
\hline HHO & 15 & 28 & 23 & 10 & 16 & 17 & 18 & 5129.8660 & 5.4900 & 43.5596 & 0.000120 \\
\hline $\mathrm{DE}$ & 30 & 28 & 23 & 10 & 16 & 17 & 18 & 5241.9298 & 6.7893 & 43.9745 & 0.000122 \\
\hline $\mathrm{HHO}$ & 30 & 28 & 23 & 10 & 16 & 17 & 18 & 5241.8414 & 7.2743 & 43.9741 & 0.000126 \\
\hline $\mathrm{DE}$ & 45 & 28 & 23 & 10 & 16 & 17 & 18 & 5372.3887 & 10.6674 & 44.3998 & 0.000146 \\
\hline $\mathrm{HHO}$ & 45 & 28 & 23 & 10 & 16 & 17 & 18 & 5372.4473 & 10.2848 & 44.4000 & 0.000141 \\
\hline $\mathrm{DE}$ & 60 & 28 & 23 & 10 & 16 & 17 & 18 & 5523.1024 & 13.533 & 44.8381 & 0.00015 \\
\hline $\mathrm{HHO}$ & 60 & 28 & 23 & 10 & 16 & 17 & 18 & 5523.0502 & 14.3174 & 44.8379 & 0.000157 \\
\hline $\mathrm{DE}$ & 75 & 28 & 23 & 10 & 16 & 17 & 18 & 5694.8965 & 22.3306 & 45.2884 & 0.000194 \\
\hline $\mathrm{HHO}$ & 75 & 28 & 23 & 10 & 16 & 17 & 18 & 5695.1901 & 18.8559 & 45.2891 & 0.000167 \\
\hline $\mathrm{DE}$ & 90 & 28 & 23 & 10 & 16 & 17 & 18 & 5890.7949 & 23.2897 & 45.7554 & 0.000169 \\
\hline HНO & 90 & 28 & 23 & 10 & 16 & 17 & 18 & 5890.7510 & 22.2454 & 45.7553 & 0.000163 \\
\hline $\mathrm{DE}$ & 100 & 28 & 23 & 10 & 16 & 17 & 18 & 6111.5889 & 28.3368 & 46.2372 & 0.000170 \\
\hline HHO & 100 & 28 & 23 & 10 & 16 & 17 & 18 & 6111.5023 & 28.6552 & 46.2371 & 0.000172 \\
\hline $\mathrm{DE}$ & 150 & 28 & 23 & 10 & 16 & 17 & 18 & 6744.2286 & 35.2658 & 49.2563 & 0.000203 \\
\hline HHO & 150 & 28 & 23 & 10 & 16 & 17 & 18 & 6744.1441 & 35.1486 & 49.2482 & 0.000204 \\
\hline
\end{tabular}

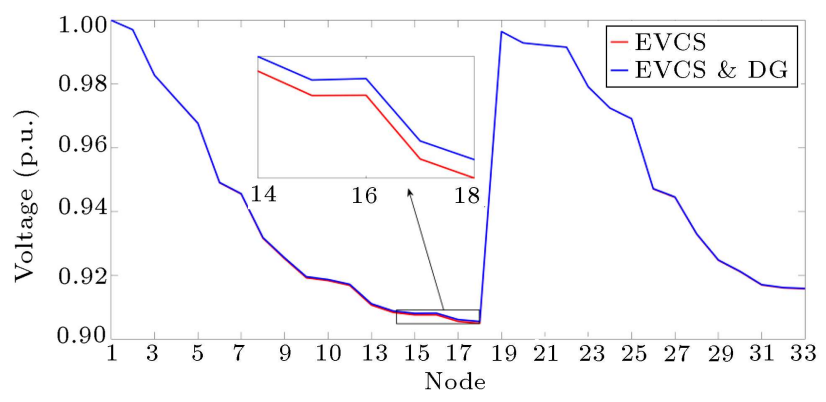

Figure 16. Voltage profile of distribution network after electric vehicle charging station allocation with and without distributed generation for $15 \%$ electric vehicle penetration.

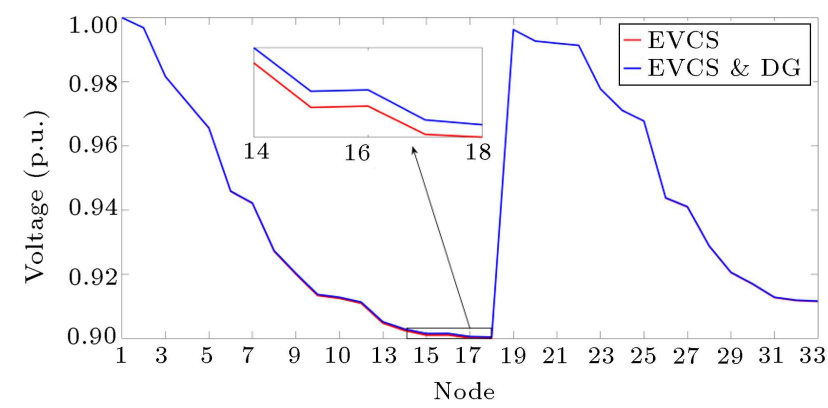

Figure 17. Voltage profile of distribution network after electric vehicle charging station allocation with and without distributed generation for $100 \%$ electric vehicle penetration.

loss and voltage deviation for two cases including 'with' and 'without' DG, respectively. In the former case (with DG), the energy loss and voltage deviation are reduced both for all the $\mathrm{EV}$ penetration levels.

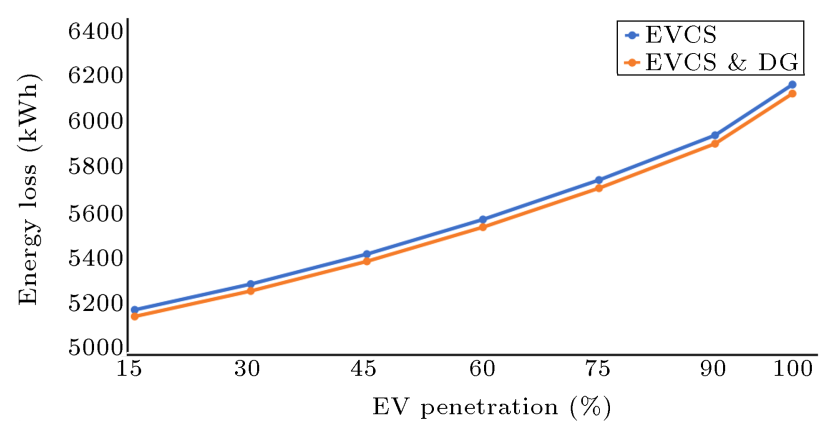

Figure 18. Energy loss comparison for only electric vehicle charging station allocation and electric vehicle charging station with distributed generation allocation for different levels of electric vehicle penetration.

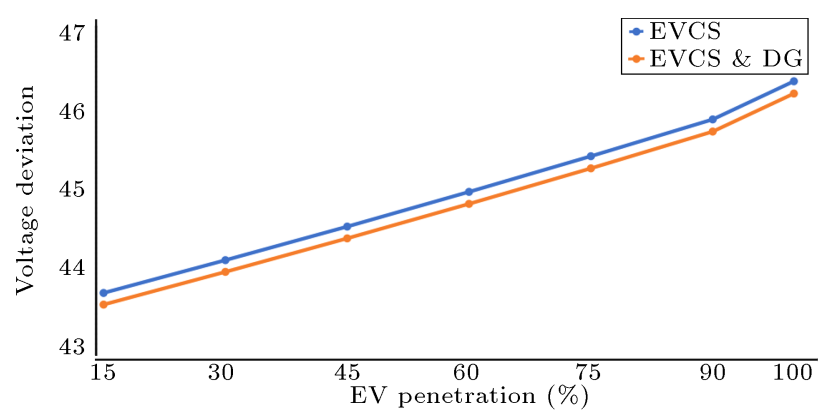

Figure 19. Voltage deviation comparison for only electric vehicle charging station allocation and electric vehicle charging station with distributed generation allocation for different electric vehicle penetration levels.

\subsubsection{Allocation considering correlations}

The correlation between different parameters makes this research more realistic and sustainable. In this work, departure time was calculated from energy 
Table 12. Allocation considering correlations for Case 7 with different levels of electric vehicle penetration with distributed generation.

\begin{tabular}{|c|c|c|c|c|c|c|c|c|c|c|c|}
\hline \multirow{3}{*}{$\begin{array}{c}\text { Technique } \\
\text { DE }\end{array}$} & \multirow{3}{*}{$\begin{array}{c}\text { EV penetration } \\
(\%)\end{array}$} & \multirow{2}{*}{\multicolumn{3}{|c|}{$\begin{array}{c}\text { EVCS } \\
\text { locations }\end{array}$}} & \multirow{2}{*}{\multicolumn{3}{|c|}{$\begin{array}{c}\text { DG } \\
\text { locations }\end{array}$}} & \multicolumn{2}{|c|}{ Energy loss (kWh) } & \multicolumn{2}{|c|}{ Voltage deviation } \\
\hline & & & & & & & & \multirow{2}{*}{$\begin{array}{c}\text { Mean } \\
5125.271\end{array}$} & \multirow{2}{*}{$\begin{array}{c}\text { SD } \\
5.0758\end{array}$} & \multirow{2}{*}{$\begin{array}{c}\text { Mean } \\
43.5572\end{array}$} & \multirow{2}{*}{$\frac{\text { SD }}{0.000114}$} \\
\hline & & 28 & 23 & 10 & 16 & 17 & 18 & & & & \\
\hline НHO & 15 & 28 & 23 & 10 & 16 & 17 & 18 & 5124.713 & 5.2442 & 43.5571 & 0.000116 \\
\hline $\mathrm{DE}$ & 30 & 28 & 23 & 10 & 16 & 17 & 18 & 5236.465 & 6.6251 & 43.9734 & 0.000121 \\
\hline $\mathrm{HHO}$ & 30 & 28 & 23 & 10 & 16 & 17 & 18 & 5236.047 & 7.0012 & 43.9733 & 0.000120 \\
\hline $\mathrm{DE}$ & 45 & 28 & 23 & 10 & 16 & 17 & 18 & 5366.098 & 10.2159 & 44.3986 & 0.000144 \\
\hline $\mathrm{HHO}$ & 45 & 28 & 23 & 10 & 16 & 17 & 18 & 5366.129 & 10.1436 & 44.3979 & 0.000143 \\
\hline $\mathrm{DE}$ & 60 & 28 & 23 & 10 & 16 & 17 & 18 & 5516.666 & 12.9856 & 44.8283 & 0.000153 \\
\hline $\mathrm{HHO}$ & 60 & 28 & 23 & 10 & 16 & 17 & 18 & 5515.988 & 13.1986 & 44.8283 & 0.000156 \\
\hline $\mathrm{DE}$ & 75 & 28 & 23 & 10 & 16 & 17 & 18 & 5687.306 & 21.7561 & 45.2715 & 0.000192 \\
\hline HHO & 75 & 28 & 23 & 10 & 16 & 17 & 18 & 5687.408 & 21.5892 & 45.2709 & 0.000165 \\
\hline $\mathrm{DE}$ & 90 & 28 & 23 & 10 & 16 & 17 & 18 & 5882.771 & 22.5924 & 45.8126 & 0.000164 \\
\hline HHO & 90 & 28 & 23 & 10 & 16 & 17 & 18 & 5882.199 & 22.3547 & 45.8119 & 0.000164 \\
\hline $\mathrm{DE}$ & 100 & 28 & 23 & 10 & 16 & 17 & 18 & 6102.063 & 27.6813 & 46.2371 & 0.000168 \\
\hline HHO & 100 & 28 & 23 & 10 & 16 & 17 & 18 & 6101.852 & 27.5127 & 46.2370 & 0.000169 \\
\hline $\mathrm{DE}$ & 100 & 28 & 23 & 10 & 16 & 17 & 18 & 6732.256 & 35.1256 & 49.2561 & 0.000201 \\
\hline HНO & 100 & 28 & 23 & 10 & 16 & 17 & 18 & 6732.196 & 35.1153 & 49.2481 & 0.000202 \\
\hline
\end{tabular}

Table 13. Comparison of Monte-Carlo Simulation (MCS), $2 \mathrm{~m}$ Point Estimation Method (2m PEM), and real data for $100 \%$ electric vehicle penetration.

\begin{tabular}{|c|c|c|c|c|c|c|c|c|c|c|c|}
\hline & \multirow{3}{*}{$\begin{array}{c}\text { Technique } \\
\text { DE }\end{array}$} & \multirow{2}{*}{\multicolumn{3}{|c|}{$\begin{array}{c}\text { EVCS } \\
\text { locations }\end{array}$}} & \multirow{2}{*}{\multicolumn{3}{|c|}{$\begin{array}{c}\text { DG } \\
\text { locations }\end{array}$}} & \multicolumn{2}{|c|}{ Energy loss (kWh) } & \multicolumn{2}{|c|}{ Voltage deviation } \\
\hline & & & & & & & & Mean & SD & Mean & SD \\
\hline \multirow{2}{*}{ MCS } & & 10 & 23 & 28 & 16 & 17 & 18 & 6119.4983 & 29.6524 & 46.2461 & 0.000175 \\
\hline & HHO & 10 & 23 & 28 & 16 & 17 & 18 & 6119.4781 & 29.5789 & 46.2456 & 0.000174 \\
\hline \multirow{2}{*}{ 2m PEM } & $\mathrm{DE}$ & 10 & 23 & 28 & 16 & 17 & 18 & 6111.5889 & 28.3368 & 46.2372 & 0.000170 \\
\hline & HHO & 10 & 23 & 28 & 16 & 17 & 18 & 6111.5023 & 28.6552 & 46.2371 & 0.000172 \\
\hline \multirow{2}{*}{ Real data } & $\mathrm{DE}$ & 10 & 23 & 28 & 16 & 17 & 18 & 6110.2547 & - & 46.2369 & - \\
\hline & HHO & 10 & 23 & 28 & 16 & 17 & 18 & 6110.2547 & - & 46.2369 & - \\
\hline
\end{tabular}

demand, which is dependent on the subsequent trip distance. Arrival SOC is correlated with arrival time, because SOC consumption depends on traffic congestion and other dynamic factors, which influence the arrival SOC. The correlation coefficient was taken as -0.99 between arrival time and arrival SOC; -0.39 between departure time and arrival time; and -0.49 between departure time and STD [88]. The coefficient value is 1 for self-correlation and 0 if there is no correlation. To manage spatial correlations between the parameters, the orthogonal transformation process [89] was attached to $2 \mathrm{~m}$ PEM and the corresponding results are shown in Table 12. It can be observed that the locations of EVCS and DG remain the same. The energy loss and the voltage deviation are reduced for all the penetration levels because of the demand change with arrival SOC, which is correlated with arrival time.

4.4.5. Comparative study of real data and MCS

The final problem that involves considering all the objectives with $100 \%$ EV penetration was solved upon incorporating MCS and real data. Results obtained by incorporating MCS, real data, and 2m PEM are shown in Table 13. The MCS-based result was obtained based on 50 scenarios. According to Table 13, the EVCS locations and DG locations do not change for MCS, $2 \mathrm{~m}$ PEM, and real data. However, the mean and SD values of energy loss and voltage deviation using MCS are higher than the $2 \mathrm{~m}$ PEM due to the mathematical approach adopted for consideration of uncertainties. 
Table 14. Solution of Case 7 with different optimization techniques for $100 \%$ electric vehicle penetration.

\begin{tabular}{|c|c|c|c|c|c|c|c|c|c|c|}
\hline \multirow{3}{*}{$\begin{array}{l}\text { Technique } \\
\text { GA }\end{array}$} & \multirow{2}{*}{\multicolumn{3}{|c|}{$\begin{array}{c}\text { EVCS } \\
\text { locations }\end{array}$}} & \multirow{2}{*}{\multicolumn{3}{|c|}{$\begin{array}{c}\text { DG } \\
\text { locations }\end{array}$}} & \multicolumn{2}{|c|}{ Energy loss (kWh) } & \multicolumn{2}{|c|}{ Voltage deviation } \\
\hline & & & & & & & \multirow{2}{*}{$\begin{array}{c}\text { Mean } \\
6111.5456\end{array}$} & \multirow{2}{*}{$\begin{array}{c}\text { SD } \\
28.4695\end{array}$} & \multirow{2}{*}{$\begin{array}{c}\text { Mean } \\
46.2596\end{array}$} & \multirow{2}{*}{$\begin{array}{c}\text { SD } \\
0.000171\end{array}$} \\
\hline & 10 & 23 & 28 & 16 & 17 & 18 & & & & \\
\hline PSO & 10 & 23 & 28 & 16 & 17 & 18 & 6111.8625 & 28.2658 & 46.3127 & 0.000172 \\
\hline GWO & 10 & 23 & 28 & 16 & 17 & 18 & 6111.6398 & 28.7123 & 46.2694 & 0.000170 \\
\hline $\mathrm{BBO}$ & 10 & 23 & 28 & 16 & 17 & 18 & 6111.7215 & 28.5632 & 46.2712 & 0.000171 \\
\hline SOS & 10 & 23 & 28 & 16 & 17 & 18 & 6111.9563 & 28.4695 & 46.3028 & 0.000173 \\
\hline HBC & 10 & 23 & 28 & 16 & 17 & 18 & 6111.5256 & 28.1259 & 46.2486 & 0.000170 \\
\hline BSA & 10 & 23 & 28 & 16 & 17 & 18 & 6111.5789 & 28.7512 & 46.2391 & 0.000171 \\
\hline HGSO & 10 & 23 & 28 & 16 & 17 & 18 & 6111.5365 & 28.4691 & 46.2549 & 0.000173 \\
\hline
\end{tabular}

Table 15. Solution of Case 7 on a 1000-bus distribution network for $100 \%$ Electric Vehicle (EV) penetration.

\begin{tabular}{ll}
\hline & $905,403,40,325,220,540,706,288,110,395,770,918,283,808,787,446,525,778,757$, \\
& $390,441,799,423,348,314,980,10,465,379,64,256,801,437,1000,939,13,231,884,214$, \\
EVCS locations & $101,30,461,775,144,504,889,591,542,57,477,922,572,331,991,385,5,555,485,943$, \\
& $264,849,106,278,646,436,378,184,610,298,617,913,49,50,242,270,519,520,336,772$, \\
& $874,193,683,2,524,150,794,240,257,22,637$
\end{tabular}

The solutions achieved using real data are also the same as the ones obtained by MCS and $2 \mathrm{~m}$ PEM, i.e., 10, 23, 28 and 16, 17, 18. However, the real data presents the solution based on the exact load demand (due to EVs) unlike the data generated from distributed function in uncertainty modeling.

The energy loss and voltage deviation achieved using the real data are close to those obtained by the $2 \mathrm{~m}$ PEM. This ensures that the solutions obtained by the stochastic method are equally acceptable and may be fit for practical implementation.

\subsubsection{Solution of the final case with other benchmarked optimization techniques}

The consideration of all the four objective functions is more realistic, and solar DGs help to improve the power system health. Therefore, Case 7, which involves simul- taneous allocation of EVCS and solar DG, was selected to be solved using different established optimization techniques to validate the final result with $100 \% \mathrm{EV}$ penetration. The selected optimization techniques are GA, PSO, GWO, BBO, SOS, HBC, BSA, and HGSO. The results are shown in Table 14 and it can be seen that all the solutions are the same.

\subsubsection{Application to a 1000-bus distribution network} To ensure the capability of this solution method, the proposed problem was solved in the case of a large distribution system, i.e., 1000-bus distribution network with 90 EVCSs and 90 DGs in the presence of 2000 $\mathrm{EV}$ in the area. Results of the allocation of EVCSs and DGs with the objective function values are shown in Table 15. The energy loss and voltage deviation are higher than those for the 33-bus network because 
the large system has more lines and loads at EVCSs. Total land cost is also higher than that for the 33-node superimposed network because of the large number of EVCSs. For the same reason, the total weightage was 42 for this system, whereas it was 2.5 for the mentioned 33-node network.

\subsubsection{Summary of the results}

Based on the analysis of the above results and general concepts used, it was found that all the four objective functions associated with EVCS placement must be considered to ensure long-term sustainability. Moreover, network operator as well as EV users can benefit from optimal locations. All the ten optimization techniques provided the same optimal results for locations of EVCS and solar DG considering the four objective functions with $100 \% \mathrm{EV}$ penetration. Therefore, it can be said that the obtained solutions are truly optimal.

Consequently, the ultimate result obtained from the analysis of all the case studies indicates that nodes 28,23 , and 10 are suitable locations for EVCS installation. The EVCSs in these locations provide minimum energy loss and voltage deviation for distribution networks. Moreover, these locations feature optimal land costs and high weightage.

As seen in Figure 20, the optimal sites of EVCS are distributed in the urban area, which are helpful for users to access the EVCS. However, all the EVCSs are not close to the blue road because the objective is to maintain low land cost. Besides, the other roads join the main blue road in the urban area. Therefore, Locations 28 and 10 that are close to green roads are able to serve the user.

According to the results and discussion, the optimal locations of solar DGs did not change at the EV penetration level. Therefore, DGs can be placed at nodes 16,17 , and 18 (Figure 20) to improve voltage profile and reduce energy loss. It can be noticed from Tables 10 and 11 that simultaneous allocation of EVCS

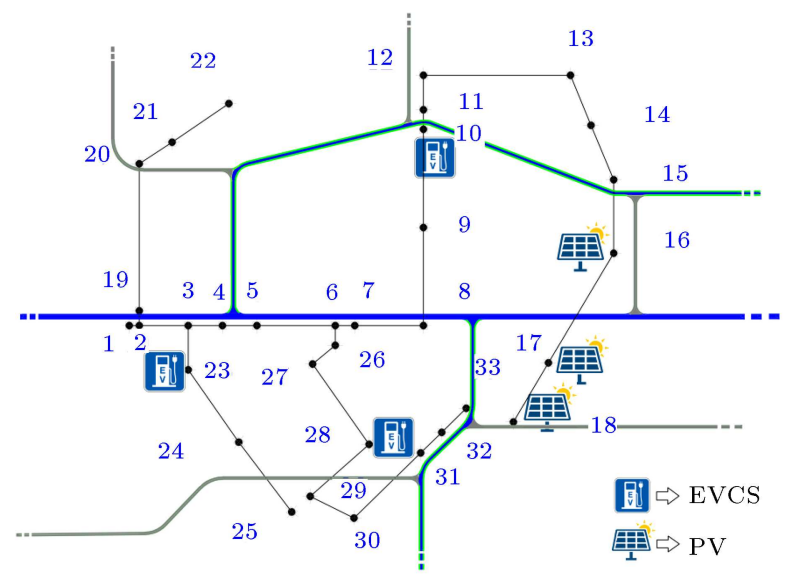

Figure 20. Optimal locations of fast-charging electric vehicle charging station and solar distributed generation. and DG reduces remarkable energy loss and voltage deviation.

Considering the uncertainties, the mean of the energy loss and voltage deviation are $6111.5023 \mathrm{kWh}$ and 46.2371, respectively, after allocating the EVCSs and solar DGs to the optimized locations. However, the low penetration of EV reduces the energy loss and voltage deviation, but the solutions for the location are the same. The land cost and weightage are $\$ 143019.80$ and 2.5, respectively, for the allocated locations of EVCS.

\section{Conclusion}

Optimal location for Electric Vehicle Charging Station (EVCSs) is one of the most important aspects of Charging Station (CS) to serve Electric Vehicle (EV) users and to keep the power system healthy. This study determined optimized locations including such aspects as energy loss and voltage deviation of the distribution system as well as weightage of the locations with their land cost in the road network. The optimal locations differed in terms of practical multi-objective solution compared to the single objective. It was observed that solutions were the same if the number of vehicles varied. Solar $P V \mathrm{~s}$ were allocated for Distributed Generation (DG) in the test system to make it renewable, thus improving the power system conditions. The same locations were found optimal for EVCSs while simultaneous allocation of EVCSs and DGs was performed. Therefore, the solutions of the multi-objective problem could be considered as efficient ones for placing the EVCS. Harris Hawks Optmization (HHO) and Differential Evolution (DE) offered the same solution for all the cases and confirmed that the solutions were optimal. In terms of convergence, the HHO's convergence speed was higher than the DE. The final case of simultaneous allocation of EVCS and solar DG with consideration of all the four objective functions was solved with 8 other established optimization techniques that provided the same optimal solutions. The solutions were much more practical after considering all the uncertainties related to EV and $P V$. This work can be extended to include reliability study and network expansion requirements. It is recommended that future researches would use the existing fuel station to place a charging facility considering the safety norms.

\section{References}

1. Solaymani, $\mathrm{S}$. " $\mathrm{CO}_{2}$ emissions patterns in 7 top carbon emitter economies: The case of transport sector", Energy, 168, pp. 989-1001 (2019).

2. Lee, S.H., Lee, T.H., Jeong, S.M., et al. "Economic analysis of a 600 mwe ultra supercritical circulating 
fluidized bed power plant based on coal tax and biomass co-combustion plans", Renew. Energy, 138, pp. 121-127 (2019).

3. Cui, Q., Weng, Y., and Tan, C.-W. "Electric vehicle charging station placement method for urban areas", IEEE Trans. Smart Grid, 10(6), pp. 6552-6565 (2019).

4. Deb, S., Tammi, K., Kalita, K., et al. "Charging station placement for electric vehicles: A case study of Guwahati city, India", IEEE Access, 7, pp. 100270100282 (2019).

5. Giménez-Gaydou, D.A., Ribeiro, A.S.N., Gutiérrez, J., et al. "Optimal location of battery electric vehicle charging stations in urban areas: A new approach", Int. J. Sustain. Transp., 10(5), pp. 393-405 (2016).

6. Baouche, F., Billot, R., Trigui, R., et al. "Efficient allocation of electric vehicles charging stations: Optimization model and application to a dense urban network", IEEE Intell. Transp. Syst. Mag., 6(3), pp. 33-43 (2014).

7. Dong, G., Ma, J., Wei, R., et al. "Electric vehicle charging point placement optimisation by exploiting spatial statistics and maximal coverage location models", Transp. Res. Part Transp. Environ., 67, pp. 7788 (2019).

8. Xi, X., Sioshansi, R., and Marano, V. "Simulationoptimization model for location of a public electric vehicle charging infrastructure", Transp. Res. Part Transp. Environ., 22, pp. 60-69 (2013).

9. Wu, F. and Sioshansi, R. "A stochastic flow-capturing model to optimize the location of fast-charging stations with uncertain electric vehicle flows", Transp. Res. Part Transp. Environ., 53, pp. 354-376 (2017).

10. Jia, L., Hu, Z., Song, Y., et al. "Optimal siting and sizing of electric vehicle charging stations", 2012 IEEE Int. Electr. Veh. Conf., IEEE, Greenville, SC, USA, pp. 1-6 (2012).

11. He, Y., Kockelman, K.M., and Perrine, K.A. "Optimal locations of U.S. fast charging stations for longdistance trip completion by battery electric vehicles", J. Clean. Prod., 214, pp. 452-461 (2019).

12. Zhang, H., Tang, L., Yang, C., et al. "Locating electric vehicle charging stations with service capacity using the improved whale optimization algorithm", $A d v$. Eng. Inform., 41, p. 100901 (2019).

13. Micari, S., Polimeni, A., Napoli, G., et al. "Electric vehicle charging infrastructure planning in a road network", Renew. Sustain. Energy Rev., 80, pp. 98108 (2017).

14. Kong, W., Luo, Y., Feng, G., et al. "Optimal location planning method of fast charging station for electric vehicles considering operators, drivers, vehicles, traffic flow and power grid", Energy, 186, p. 115826 (2019).

15. Guo, S. and Zhao, H. "Optimal site selection of electric vehicle charging station by using fuzzy TOPSIS based on sustainability perspective", Appl. Energy, 158, pp. 390-402 (2015).
16. Hosseini, S. and Sarder, M. "Development of a Bayesian network model for optimal site selection of electric vehicle charging station", Int. J. Electr. Power Energy Syst., 105, pp. 110-122 (2019).

17. Lam, A.Y.S., Leung, Y.-W., and Chu, X. "Electric vehicle charging station placement: Formulation, complexity, and solutions", IEEE Trans. Smart Grid, 5(6), pp. 2846-2856 (2014).

18. He, J., Yang, H., Tang, T.-Q., et al. "An optimal charging station location model with the consideration of electric vehicle's driving range", Transp. Res. Part C Emerg. Technol, 86, pp. 641-654 (2018).

19. Zhu, Z.-H., Gao, Z.-Y., Zheng, J.-F., et al. "Charging station location problem of plug-in electric vehicles", J. Transp. Geogr., 52, pp. 11-22 (2016).

20. Tang, X., Liu, J., Wang, X., et al. "Electric vehicle charging station planning based on weighted voronoi diagram", Proceedings 2011 International Conference on Transportation, Mechanical, and Electrical Engineering (TMEE), IEEE, pp. 1297-1300 (2011).

21. Andrews, M., Dog, M.K., and Labs, A.-L.B. "Modeling and optimization for electric vehicle charging infrastructure", IEEE Innovative Smart Grid Technologies Conference, pp. 1-10 (2013).

22. Xiong, Y., Gan, J., An, B., et al. "Optimal electric vehicle fast charging station placement based on game theoretical framework", IEEE Trans. Intell. Transp. Syst., 19(8), pp. 2493-2504 (2018).

23. Frade, I., Ribeiro, A., Gonçalves, G., et al. "Optimal location of charging stations for electric vehicles in a neighborhood in Lisbon, Portugal", Transp. Res. Rec. J. Transp. Res. Board, 2252(1), pp. 91-98 (2011).

24. Riemann, R., Wang, D.Z.W., and Busch, F. "Optimal location of wireless charging facilities for electric vehicles: Flow-capturing location model with stochastic user equilibrium", Transp. Res. Part C Emerg. Technol., 58, pp. 1-12 (2015).

25. Shahraki, N., Cai, H., Turkay, M., et al. "Optimal locations of electric public charging stations using real world vehicle travel patterns", Transp. Res. Part Transp. Environ., 41, pp. 165-176 (2015).

26. Liu, Z., Zhang, W., Ji, X., et al. "Optimal planning of charging station for electric vehicle based on particle swarm optimization", IEEE PES Innov. Smart Grid Technol., IEEE, Tianjin, China, pp. 1-5 (2012).

27. Infante, W., Ma, J., Han, X., et al. "Optimal recourse strategy for battery swapping stations considering electric vehicle uncertainty", IEEE Trans. Intell. Transp. Syst., 21(4), pp. 1-11 (2019).

28. Sarparandeh, M.H., Kazemi, M., and Ehsan, M. "Medium-term planning of vehicle-to-grid aggregators for providing frequency regulation service", Sci. Iran., 27(3), pp. 1413-1423 (2018).

29. Mohammadi-Ivatloo, B., Aliasgahri, P., and Abapour, M. "Risk-based cooperative scheduling of demand response and electric vehicle aggregators", Sci. Iran., 26(6), pp. 3571-3581 (2019). 
30. Bhatti, A.R., Salam, Z., Sultana, B., et al. "Optimized sizing of photovoltaic grid-connected electric vehicle charging system using particle swarm optimization", Int. J. Energy Res., 43(1), pp. 500-522 (2019).

31. Zheng, Y., Dong, Z.Y., Xu, Y., et al. "Electric vehicle battery charging/swap stations in distribution systems: Comparison study and optimal planning", IEEE Trans. Power Syst., 29(1), pp. 221-229 (2014).

32. Moradijoz, M., Parsa Moghaddam, M., Haghifam, M.R., et al. "A multi-objective optimization problem for allocating parking lots in a distribution network", Int. J. Electr. Power Energy Syst., 46, pp. 115-122 (2013).

33. Shaaban, M.F., Mohamed, S., Ismail, M., et al. "Joint planning of smart EV charging stations and DGs in eco-friendly remote hybrid microgrids", IEEE Trans. Smart Grid, 10(5), pp. 5819-5830 (2019).

34. Atat, R., Ismail, M., Serpedin, E., et al. "Dynamic joint allocation of EV charging stations and DGs in spatio-temporal expanding grids", IEEE Access, 8, pp. $7280-7294$ (2020).

35. Yi, T., Cheng, X., Zheng, H., et al. "Research on location and capacity optimization method for electric vehicle charging stations considering user's comprehensive satisfaction", Energies, 12(10), p. 1915 (2019).

36. Moradijoz, M., Moghaddam, M.P., and Haghifam, M.R. "Optimum placement of distributed generation and parking lots for loss reduction in distribution networks", 2012 Proceedings of 17th Conference on Electrical Power Distribution, IEEE, pp. 1-5 (2012).

37. Babu, P.V.K. and Swarnasri, K. "Multi-objective optimal allocation of electric vehicle charging stations in radial distribution system using teaching learning based optimization", International Journal of Renewable Energy Research, 10(1), pp. 366-377 (2020).

38. Pal, A., Bhattacharya, A., and Chakraborty, A.K. "Allocation of EV fast charging station with V2G facility in distribution network", 2019 8th Int. Conf. Power Syst. ICPS, IEEE, Jaipur, India, pp. 1-6 (2019).

39. Liu, L., Zhang, Y., Da, C., et al. "Optimal allocation of distributed generation and electric vehicle charging stations based on intelligent algorithm and bi-level programming”, Int. Trans. Electr. Energy Syst., 30(6), e12366 (2020).

40. Luo, L., Wu, Z., Gu, W., et al. "Coordinated allocation of distributed generation resources and electric vehicle charging stations in distribution systems with vehicleto-grid interaction", Energy, 192, p. 116631 (2020).

41. Awasthi, A., Venkitusamy, K., Padmanaban, S., et al. "Optimal planning of electric vehicle charging station at the distribution system using hybrid optimization algorithm", Energy, 133, pp. 70-78 (2017).

42. Mehta, R., Verma, P., Srinivasan, D., et al. "Doublelayered intelligent energy management for optimal integration of plug-in electric vehicles into distribution systems", Appl. Energy, 233-234, pp. 146-155 (2019).
43. Shojaabadi, S., Abapour, S., Abapour, M., et al. "Optimal planning of plug-in hybrid electric vehicle charging station in distribution network considering demand response programs and uncertainties", IET Gener. Transm. Distrib., 10(13), pp. 3330-3340 (2016).

44. Liu, Z., Wen, F., and Ledwich, G. "Optimal planning of electric-vehicle charging stations in distribution systems", IEEE Trans. Power Deliv., 28(1), pp. 102110 (2013).

45. Aljaidi, M., Aslam, N., and Kaiwartya, O. "Optimal placement and capacity of electric vehicle charging stations in urban areas: Survey and open challenges", 2019 IEEE Jordan Int. Jt. Conf. Electr. Eng. Inf. Technol. JEEIT, IEEE, Amman, Jordan, pp. 238-243 (2019).

46. Davidov, S. and Pantoš, M. "Optimization model for charging infrastructure planning with electric power system reliability check", Energy, 166, pp. 886-894 (2019).

47. Sadeghi-Barzani, P., Rajabi-Ghahnavieh, A., and Kazemi-Karegar, H. "Optimal fast charging station placing and sizing", Appl. Energy, 125, pp. 289-299 (2014).

48. Liu, X. and Bie, Z. "Optimal allocation planning for public EV charging station considering AC and DC integrated chargers", Energy Procedia, 159, pp. 382387 (2019).

49. Andrade, J., Ochoa, L.F., and Freitas, W. "Regionalscale allocation of fast charging stations: travel times and distribution system reinforcements", IET Gener. Transm. Distrib., 14(19), pp. 4225-4233 (2020).

50. Wang, G., Xu, Z., Wen, F., et al. "Traffic-constrained multiobjective planning of electric-vehicle charging stations", IEEE Trans. Power Deliv., 28(4), pp. 23632372 (2013).

51. Zhang, Y., Zhang, Q., Farnoosh, A., et al. "GISbased multi-objective particle swarm optimization of charging stations for electric vehicles", Energy, 169, pp. 844-853 (2019).

52. Lin, X., Sun, J., Ai, S., et al. "Distribution network planning integrating charging stations of electric vehicle with V2G", Int. J. Electr. Power Energy Syst., 63, pp. 507-512 (2014).

53. Hadian, E., Akbari, H., Farzinfar, M., et al. "Optimal allocation of electric vehicle charging stations with adopted smart charging/discharging schedule", IEEE Access, 8, pp. 196908-196919 (2020).

54. Dai, Q., Liu, J., and Wei, Q. "Optimal photovoltaic/battery energy storage/electric vehicle charging station design based on multi-agent particle swarm optimization algorithm", Sustainability, 11(7), p. 1973 (2019).

55. Yan, Q., Zhang, B., and Kezunovic, M. "Optimized operational cost reduction for an EV charging station integrated with battery energy storage and $P V$ generation", IEEE Trans. Smart Grid, 10(2), pp. 2096-2106 (2019). 
56. Gong, D., Tang, M., Buchmeister, B., et al. "Solving location problem for electric vehicle charging stationsA sharing charging model", IEEE Access, 7, pp. 138391-138402 (2019).

57. Kasturi, K., Nayak, M., and Nayak, C. "PV/BESS for support electric vehicle charging station integration in a capacity constrained power distribution grid using MCTLBO", Sci. Iran., 29(3), pp. 1437-1454 (2020).

58. Mozafar, M.R., Moradi, M.H., and Amini, M.H. "A simultaneous approach for optimal allocation of renewable energy sources and electric vehicle charging stations in smart grids based on improved GA-PSO algorithm", Sustain. Cities Soc., 32, pp. 627-637 (2017).

59. Pashajavid, E. and Golkar, M.A. "Optimal placement and sizing of plug in electric vehicles charging stations within distribution networks with high penetration of photovoltaic panels", J. Renew. Sustain. Energy, 5(5), p. 053126 (2013).

60. Jin, C., Sheng, X., and Ghosh, P. "Optimized electric vehicle charging with intermittent renewable energy sources", IEEE J. Sel. Top. Signal Process., 8(6), pp. 1063-1072 (2014).

61. Sokorai, P., Fleischhacker, A., Lettner, G., et al. "Stochastic modeling of the charging behavior of electromobility", World Electr. Veh. J., 9(3), p. 44 (2018).

62. Faddel, S., Aldeek, A., Al-Awami, A.T., et al. "Ancillary services bidding for uncertain bidirectional V2G using fuzzy linear programming", Energy, 160, pp. 986-995 (2018).

63. Wu, F. and Sioshansi, R. "A stochastic flow-capturing model to optimize the location of fast-charging stations with uncertain electric vehicle flows", Transportation Research Part D: Transport and Environment, 53, pp. 354-376 (2017).

64. Rezaee, S., Farjah, E., and Khorramdel, B. "Probabilistic analysis of plug-in electric vehicles impact on electrical grid through homes and parking lots", IEEE Trans. Sustain. Energy, 4(4), pp. 1024-1033 (2013).

65. Banol Arias, N., Tabares, A., Franco, J.F., et al. "Robust joint expansion planning of electrical distribution systems and EV charging stations", IEEE Trans. Sustain. Energy, 9(2), pp. 884-894 (2018).

66. Shafie-khah, M., Heydarian-Forushani, E., Osorio, G.J., et al. "Optimal behavior of electric vehicle parking lots as demand response aggregation agents", IEEE Trans. Smart Grid, 7(6), pp. 2654-2665 (2016).

67. Shojaabadi, S., Abapour, S., Abapour, M., et al. "Optimal planning of plug-in hybrid electric vehicle charging station in distribution network considering demand response programs and uncertainties", IET Gener. Transm. Distrib., 10(13), pp. 3330-3340 (2016).

68. Shojaabadi, S. "Simultaneous planning of plug-in hybrid electric vehicle charging stations and wind power generation in distribution networks considering uncertainties", Renew. Energy, 99, pp. 237-252 (2016).
69. Saha, A., Bhattacharya, A., Das, P., et al. "A novel approach towards uncertainty modeling in multiobjective optimal power flow with renewable integration", Int. Trans. Electr. Energy Syst., 29(12), e12136 (2019).

70. Sharma, S., Bhattacharjee, S., and Bhattacharya, A. "Probabilistic operation cost minimization of microgrid", Energy, 148, pp. 1116-1139 (2018).

71. Hong, H.P. "An efficient point estimate method for probabilistic analysis", Reliab. Eng. Syst. Saf., 59(3), pp. 261-267 (1998).

72. Storn, R. and Price, K. "Differential evolution - A simple and efficient adaptive scheme for global optimization over continuous spaces", Journal of Global Optimization, 11(4), pp. 341-359 (1997).

73. Abou El Ela, A.A., Abido, M.A., and Spea, S.R. "Optimal power flow using differential evolution algorithm", Electr. Power Syst. Res., 80(7), pp. 878-885 (2010).

74. Heidari, A.A., Mirjalili, S., Faris, H., et al. "Harris hawks optimization: Algorithm and applications", Future Gener. Comput. Syst., 97, pp. 849-872 (2019).

75. Pal, A., Bhattacharya, A., and Chakraborty, A.K. "Allocation of electric vehicle charging station considering uncertainties", Sustain. Energy Grids Netw., 25, p. $100422(2021)$.

76. Keane, A. and O'Malley, M. "Optimal allocation of embedded generation on distribution networks", IEEE Trans. Power Syst., 20(3), pp. 1640-1646 (2005).

77. Mehta, R., Srinivasan, D., Khambadkone, A.M., et al. "Smart charging strategies for optimal integration of plug-in electric vehicles within existing distribution system infrastructure", IEEE Trans. Smart Grid, 9(1), pp. 299-312 (2018).

78. Bessa, R.J., Matos, M.A., Soares, F.J., et al. "Optimized bidding of a $\mathrm{EV}$ aggregation agent in the electricity market", IEEE Trans. Smart Grid, 3(1), pp. 443-452 (2012).

79. Sultana, S. and Roy, P.K. "Oppositional krill herd algorithm for optimal location of distributed generator in radial distribution system", Int. J. Electr. Power Energy Syst., 73, pp. 182-191 (2015).

80. Soroudi, A., Aien, M., and Ehsan, M. "A probabilistic modeling of photo voltaic modules and wind power generation impact on distribution networks", IEEE Syst. J., 6(2), pp. 254-259 (2012).

81. Khemakhem, S., Rekik, M., and Krichen, L. "Double layer home energy supervision strategies based on demand response and plug-in electric vehicle control for flattening power load curves in a smart grid", Energy, 167, pp. 312-324 (2019).

82. Ray, S., Bhattacharya, A., and Bhattacharjee, S. "Optimal placement of switches in a radial distribution network for reliability improvement", Int. J. Electr. Power Energy Syst., 76, pp. 53-68 (2016).

83. Sharma, S., Bhattacharjee, S., and Bhattacharya, A. "Quasi-oppositional swine influenza model based optimization with quarantine for optimal allocation 
of DG in radial distribution network", Int. J. Electr. Power Energy Syst., 74, pp. 348-373 (2016).

84. Amiri, S.S., Jadid, S., and Saboori, H. "Multiobjective optimum charging management of electric vehicles through battery swapping stations", Energy, 165, pp. 549-562 (2018).

85. Collin, R., Miao, Y., Yokochi, A., et al. "Advanced electric vehicle fast-charging technologies", Energies, 12(10), p. 1839 (2019).

86. Mohamed, A., Salehi, V., Ma, T., et al. "Realtime energy management algorithm for plug-in hybrid electric vehicle charging parks involving sustainable energy", IEEE Trans. Sustain. Energy, 5(2), pp. 577586 (2014).

87. Bodo, N., Levi, E., Subotic, I., et al. "Efficiency evaluation of fully integrated on-board EV battery chargers with nine-phase machines", IEEE Trans. Energy Convers., 32(1), pp. 257-266 (2017).

88. Sarabi, S., Davigny, A., Courtecuisse, V., et al. "Potential of vehicle-to-grid ancillary services considering the uncertainties in plug-in electric vehicle availability and service/localization limitations in distribution grids", Appl. Energy, 171, pp. 523-540 (2016).

89. Morales, J.M., Baringo, L., Conejo, A.J., et al. "Probabilistic power flow with correlated wind sources", IET Gener. Transm. Distrib., 4(5), pp. 641-651 (2010).

\section{Biographies}

Arnab Pal received the BTech degree in Electrical Engineering from the MAKAUT (formerly known as WBUT), West Bengal, India in 2016 and MTech degree in Power System specialization from the National Institute of Technology Agartala, India in 2018. He is now a $\mathrm{PhD}$ research scholar at the Department of Electrical Engineering at National Institute of Technology Agartala. His areas of interest include electric vehicle, distribution system, distributed generation, renewables, and power system optimization.

Aniruddha Bhattacharya did his BSc in Electrical Engineering from Regional Institute of Technology, Jamshedpur, India in 2000 as well as MEE and PhD in Electrical Power System from Jadavpur University, Kolkata, India in 2008 and 2011, respectively. His employment experiences include Siemens Metering Limited, India; Jindal Steel \& Power Limited, Raigarh, India; Bankura Unnyani Institute of Engineering, India; Dr. B. C. Roy Engineering College, India; NIT Agartala, India. He is currently an Assistant Professor at the Electrical Engineering Department, NIT Durgapur, India. His areas of interest include optimal power flow, hydrothermal scheduling, power system stability, power system optimization, and electric vehicle.

Ajoy Kumar Chakraborty completed his BE (Hons) from Jadavpur University, MTech in Power System from IIT Kharagpur, and $\mathrm{PhD}$ in Electrical Engineering from Jadavpur University. Fourteen years of industrial experience in CESC, Kolkata and Tinplate Company of India Limited (A Tata Enterprise) at Jamshedpur. He has around 28 years of experience in Teaching and Research. He has more than 100 publications in national and international journals and conferences. The author is currently serving as a Professor at NIT Agartala. His areas of interest include power system, distributed generation, smart grid, electric vehicle, and optimization. 